University of Nebraska - Lincoln

DigitalCommons@University of Nebraska - Lincoln

Faculty Publications, Department of Psychology

Psychology, Department of

$11-2009$

\title{
Understanding Child Sexual Behavior Problems: A Developmental Psychopathology Framework
}

\author{
Natasha Elkovitch \\ University of Nebraska-Lincoln, nelkovitch@huskers.unl.edu \\ Robert D. Latzman \\ University of Mississippi Medical Center, rlatzman@psychiatry.umsmed.edu \\ David J. Hansen \\ Univertsity of Nebraska-Lincoln, dhansen1@unl.edu \\ Mary Fran Flood \\ University of Nebraska-Lincoln, mflood2@unl.edu
}

Follow this and additional works at: https://digitalcommons.unl.edu/psychfacpub

Part of the Psychiatry and Psychology Commons

Elkovitch, Natasha; Latzman, Robert D.; Hansen, David J.; and Flood, Mary Fran, "Understanding Child Sexual Behavior Problems: A Developmental Psychopathology Framework" (2009). Faculty Publications, Department of Psychology. 403.

https://digitalcommons.unl.edu/psychfacpub/403

This Article is brought to you for free and open access by the Psychology, Department of at DigitalCommons@University of Nebraska - Lincoln. It has been accepted for inclusion in Faculty Publications, Department of Psychology by an authorized administrator of DigitalCommons@University of Nebraska - Lincoln. 


\title{
Understanding Child Sexual Behavior Problems: A Developmental Psychopathology Framework
}

\author{
Natasha Elkovitch, ${ }^{*}$ Robert D. Latzman, ${ }^{\dagger}$ David J. Hansen, ${ }^{*}$ and Mary Fran Flood * \\ * Department of Psychology, University of Nebraska-Lincoln, 238 Burnett Hall, Lincoln, NE 68588, U.S.A.; \\ emails: nelkovitch@huskers.unl.edu (Elkovitch), dhansen1@unl.edu (Hansen),mflood2@unl.edu (Flood) \\ † Department of Psychiatry and Human Behavior, University of Mississippi Medical Center, \\ 2500 North State St., Jackson, MS 39216, U.S.A.; email: rlatzman@psychiatry.umsmed.edu
}

Corresponding author - N. Elkovitch

\begin{abstract}
Children exhibiting sexual behavior have increasingly gained the attention of child welfare and mental health systems, as well as the scientific community. While a heterogeneous group, children with sexual behavior problems consistently demonstrate a number of problems related to adjustment and overall development. In order to appropriately intervene with these children, a comprehensive understanding of etiology is imperative. The overarching goal of the present paper is to review the extant research on mechanisms associated with the development of problematic sexual behavior in childhood within a developmental psychopathology framework. What is known about normative and nonnormative sexual behavior in childhood is reviewed, highlighting definitional challenges and age-related developmental differences. Further, the relationship between child sexual abuse and child sexual behavior problems is discussed, drawing attention to factors impacting this relationship. Risk factors for child sexual behavior problems, beyond that of sexual abuse, are also reviewed utilizing a transactional-ecological framework. Finally, we conclude with a discussion of implications of a developmental psychopathology perspective on problematic child sexual behaviors to inform future research and intervention efforts. Such implications include the need for attention to normative childhood sexual behavior, developmental sensitivity, and examinations of ecological domain in concert.
\end{abstract}

Keywords: child sexual behavior, normative, problematic, developmental psychopathology, risk factors, child sexual abuse

\section{Contents}

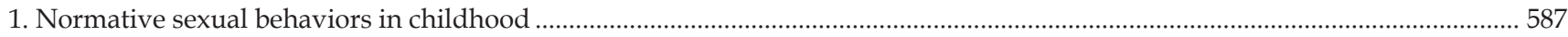

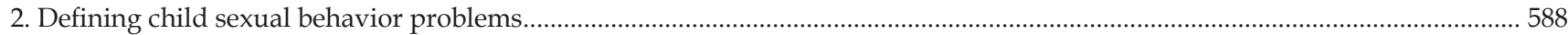

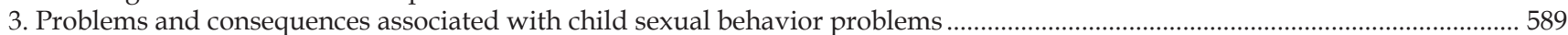

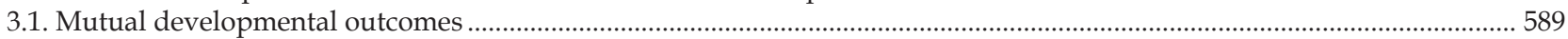

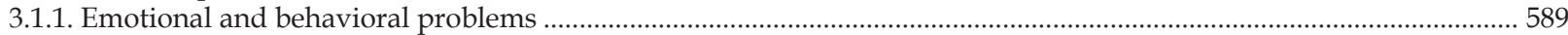

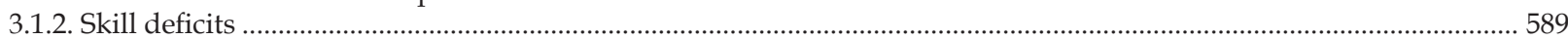

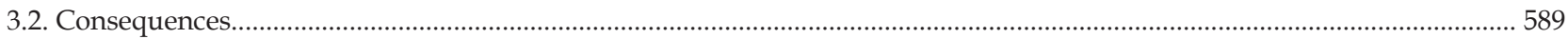

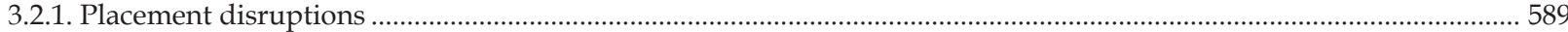

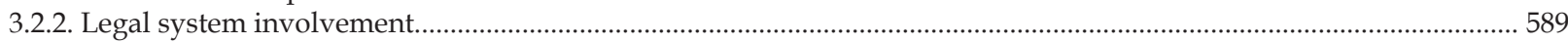

4. Development of child sexual behavior problems................................................................................................................... 589

4.1. Sexual abuse as a risk factor for the development of child sexual behavior problems ..........................................................5 590

4.1.1. Risk factors for sexual behavior problems in samples of sexually abused children ................................................... 591

4.2. Factors beyond child sexual abuse associated with the development of child sexual behavior problems .......................... 593

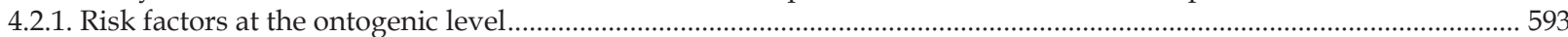

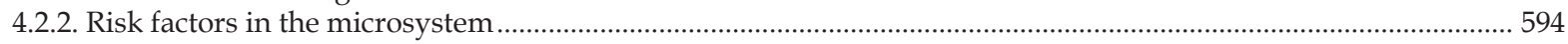

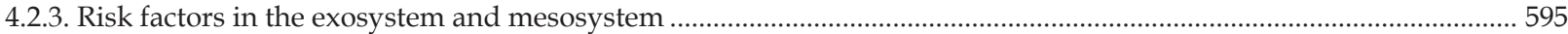

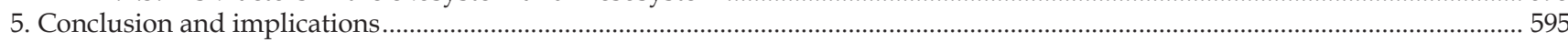

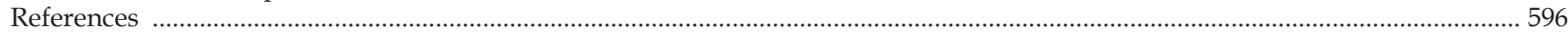


Child welfare and mental health systems have increasingly devoted attention to developmentally inappropriate and unexpected sexual behavior by children aged 12 years and younger (Araji, 1997; Chaffin et al., 2002). Increased attention was initially fueled by research demonstrating a significant association between child sexual abuse and subsequent sexualized behaviors (e.g., Friedrich, 1993; Kendall-Tackett et al., 1993). However, more recent research suggests that while sexual abuse is a significant etiological factor in the onset of problematic sexual behavior in children, it is not essential (e.g., Bonner et al., 1999; Silovsky \& Niec, 2002). This research has emphasized the etiology and maintenance of problematic child sexual behaviors as including factors across a number of domains, including biological, familial, economic and cultural (Friedrich et al., 2001, 2003). While the scope of the literature on child sexual behavior is growing, there is a pressing need for a unifying theoretical framework to organize the extant data on the development of sexual behavior problems (SBP) in childhood and to guide future research. A perspective rooted in developmental psychopathology provides such a framework.

The purpose of the present review is to broaden the conceptualization of the possible etiology of child sexual behavior problems (CSBP) by examining the existing literature from a developmental psychopathology perspective. Developmental psychopathology is an integrative discipline which attempts to understand psychopathology within a developmental, lifespan framework (Cicchetti, 1993; Rutter \& Sroufe, 2000). As a "microparadigm" (Achenbach, 1990), developmental psychopathology strives to integrate knowledge across disciplines and domains, rather than supporting a single theory that would account for all developmental phenomena (Cicchetti, 1993; Rutter \& Sroufe, 2000).

A guiding principle of developmental psychopathology is that maladaptive behavior must be examined in relation to what may be considered normative for a given developmental period. Its main focus is to highlight developmental processes and the importance and complexity of risk and protective factors across a number of ecological domains (Belsky, 1993; Bronfenbrenner, 1979; Cicchetti \& Lynch, 1993), including biological, familial, economic and cultural in understanding developmental changes. Rather than the result of a single causal factor, children's development is conceptualized as constantly being influenced by multiple interacting factors both within and across domains (Cicchetti \& Rizley, 1981; Sameroff \& Chandler, 1975). Thus, an adequate model for conceptualizing the etiology of psychopathology or problematic behaviors must be multifaceted and developmental, allowing for numerous pathways to both adaptive and maladaptive outcomes. This framework emphasizes individual differences in patterns of adaptation over time; thus, a single source of influence may lead to diverse outcomes (i.e., multifinality), and different patterns of early experience may lead to the same outcome (i.e., equifinality) (Cicchetti \& Rogosch, 1996).

Our overarching goal in this article is to elucidate those aspects of developmental psychopathology that we view as integral toward understanding the development of child (aged 12 years and younger) sexual behavior problems. The current review aims to provide a unifying theoretical framework, albeit preliminary, that may help stimulate future empirical research and inform both intervention and prevention efforts. First, we review what is known about normative and nonnormative sexual behavior in childhood. Highlighted are definitional challenges, age-related developmental differences, and the contextual influence of culture. Second, we review what is known about the influence of risk factors across a number of transactional-ecological domains in the development of CSBP, drawing attention to the twin principles of multifinality and equifinality. Finally, we conclude with a discussion of empirical implications of a developmental psychopathology perspective on problematic child sexual behaviors to inform future research and intervention efforts.

\section{Normative sexual behaviors in childhood}

Our understanding of normative sexual development and behaviors in childhood is fairly limited. Historically, preadolescent children have been regarded as asexual, and any evidence of sexual behavior has been questioned as a symptom of sexual abuse (Gordon \& Schroeder, 1995). However, developmental research indicates that the display of certain sexual behaviors in childhood are expected and developmentally appropriate (Friedrich et al., 1991, 1992, 2001; Larsson \& Svedin, 2002a; Lindblad et al., 1995; Sandfort \& Cohen-Kettenis, 2000). A short review of this research is presented below; readers are urged to consult Bancroft (2003) for a more through review of normative sexual development, including the historical progression of this work and related theoretical issues.

Empirical studies on sexual behavior in childhood have typically been approached in one of two ways: informant reports from parent/guardians or daycare providers or retrospective studies with adolescents/adults. Investigations of young children almost solely rely on informant reports, and typically utilize either the sexual behavior items from the Child Behavior Checklist (CBCL; Achenbach, 1991), or more commonly, one of the versions of the Child Sexual Behavior Inventory (CSBI; Friedrich, 1991, 1993, 1997). The popularity of the latter measure, used in studies examining both normative and nonnormative sexual behavior, allows for comparisons between studies. Regardless of measure used, research clearly indicates that parents and daycare providers report a broad range of child sexual behaviors, from low-frequency and specific behaviors, to high-frequency and more general behaviors (Friedrich et al., 1991, 1998, 2000; Lindblad et al., 1995; Schoentjes et al., 1999).

Low-frequency behaviors found using parent reports include behaviors that are intrusive, aggressive, or more imitative of adult sexual behavior, such as attempted intercourse, oral-genital contact, masturbating with an object, and inserting objects into vagina/rectum (Friedrich et al., 1991, 1998; Schoentjes et al., 1999). While rare (typically $<3 \%$ of children in community samples) throughout childhood, these behaviors are reported to occur in nearly all investigations utilizing the CSBI (Friedrich et al., 1991, 1998, 2000; Lindblad et al., 1995; Schoentjes et al., 1999). These behaviors, typically considered nonnormative or problematic, will be discussed further in the next section.

High-frequency child sexual behaviors reported by parents include self-stimulating behaviors (e.g., touching genitals in public/ home), exhibitionism (e.g., exposing genitals to others), voyeurism (e.g., attempting to look at other people when nude) and behaviors related to personal boundaries (e.g., standing too close to others). Of these, solitary, self-stimulating behaviors are reported to be the most frequently observed. However, there is some inconsistency regarding developmental trends in the incidence of genital touching. Studies utilizing parent observations tend to report a decline in sexual behavior in general, and self-stimulation in particular, with age. For example, in Friedrich et al.'s (1998) normative sample of children $(n=1114), 60.2 \%$ of 2 - to 5 -year-old boys and $43.8 \%$ of girls of the same age range were reported by their female caregivers to engage in genital touching. The prevalence of these behaviors steadily dropped with age; $39.8 \%$ of the boys and $20.7 \%$ of girls in the 6- to 9-year-old age group were observed touching their genitals. Percentages were even lower in the 10- to 12-year-old age group (1.1\% of boys, $2.2 \%$ of girls).

Teachers at nursery and elementary schools, however, consistently report observing a lower frequency of genital touching than do parents (Larsson \& Svedin, 2002a; Lindblad et al., 1995; Lopez Sanchez et al., 2002). For example, only $5 \%$ of a sample of Swedish daycare teachers reported observing 3- to 6-year-old children engaging in genital touching, as compared to $43 \%$ of the parents of these children (Larsson \& Svedin, 2002a). In contrast to informant ratings altogether, studies that utilize retrospective reports often 
find an increase in self-stimulating behavior in the years preceding puberty, particularly among boys (Bancroft, Reynolds \& Herbenick, 2003; Lopez-Sanchez et al., 2002). It is likely that these conflicting results reflect the fact that older children are more aware of the "sexual taboo," and exercise restraint in where and when they engage in these behaviors (Bancroft et al., 2003).

As noted above, some interpersonal sexual behaviors, such as exhibitionism and voyeurism, have been commonly reported by parents and daycare providers. In one Flemish (Schoentjes et al., 1999), two Dutch (Friedrich et al., 2000; Lindblad et al., 1995), and two American (Friedrich et al., 1991, 1998) samples, 25 to $63 \%$ of children age 2 to 6 years were reported trying to look at other people when nude or undressing, standing too close to others, and touching female breasts. These behaviors are also among the most commonly reportedly behaviors in 6- to 9-year-old children. In fact, 20 to $29 \%$ of children in this age group are reported trying to look at others when they are nude/undressing. Again, the prevalence of these behaviors declines with age with 6 to $19 \%$ of children aged 10 to 12 engaging in this behavior (Friedrich et al., 1998). Thus, based on parent and daycare provider report, it appears that behaviors in all three categories (exhibitionism, voyeurism, and personal boundaries) decrease with age.

In contrast, a number of other sexual behaviors have been found to become more frequent with age. These behaviors include showing interest in the opposite sex, asking questions about sexuality, looking at nude pictures, drawing sexual parts, using sexual words, and expressing an interest in nudity on television (Friedrich et al., 1991, 1998; Sandfort \& Cohen-Kettenis, 2000; Schoentjes et al., 1999). For example, in a sample of children aged 2 to 12 years, Friedrich et al. (1998) found that 5\% of children aged 2 to 5 were reported by their female caregivers to express an interest in television nudity, whereas this behavior was reported in $15 \%$ of the children aged 10 to 12 . To date, these behaviors have not been assessed via retrospective report.

Parent reports have also been used to assess the frequency of childhood interpersonal sexual behaviors often placed under the umbrella terms "sexual games" or "sexual play" (Gordon \& Schroeder, 1995; Lamb \& Coakley, 1993). Four international studies, which have all been conducted within the last decade, included a single question about whether informants observed children playing "doctors-games" (Larsson \& Svedin, 2002a; Lopez-Sanchez et al., 2002; Sandfort \& Cohen-Kettenis, 2000; Schoentjes et al., 1999). In all of these studies, sexual play was frequently observed, but with varying prevalence rates. The highest prevalence was found in a Spanish sample of children aged 0 to 11 years; $78 \%$ of parents reported having seen their child engage in a sexual game. In contrast, $55 \%$ of boys' parents and $65 \%$ of girls' parents in a Dutch sample of 0 - to 11-year-olds reported observing their child engage in a "doctors-game" (Sandfort \& Cohen-Kettenis, 2000). Larsson and Svedin (2002a) examined a more specific age range; in their sample of 3- to 6-year-old Swedish children, 37\% of boys and $48 \%$ of girls were reported by their parents engaging in this behavior. Only one study, utilizing a Flemish sample, examined developmental trends (Schoentjes et al., 1999). While 53\% of children aged 2 to 5 years were reportedly observed engaging in sexual play, this decreased to $39 \%$ and $15 \%$ in the 6- to 9-year-olds and 10 -to 11-year-olds, respectively.

Nonetheless, it is plausible that these prevalence figures, determined via informant-report, underestimate the actual incidence of sexual contact between children, particularly in the older age groups. Some parents may be unwilling to report observed sexual behavior (Larsson \& Svedin, 2002a), or may have limited opportunity to observe their child engage in interpersonal sexual behaviors. Further, it has been found that mothers with more years of education are likely to report more sexual behavior in their children than are less educated mothers (Friedrich et al., 1991), and mothers with a history of sexual abuse may be even more prone to over- or un- der-report sexual behavior in their children (Friedrich et al., 2003). Finally, as noted above, older children may exercise more restraint and conceal these behaviors from adult view (Bancroft et al, 2003).

To address the limitations of informant-report, retrospective reports have been used to assess the frequency with which young adults remember engaging in sexual behaviors with other children (Goldman \& Goldman, 1988; Haugaard, 1996; Kilpatrick, 1986; Lamb \& Coakley, 1993; Larsson \& Svedin, 2002b; Lopez-Sanchez et al., 2002; Reynolds et al., 2003). Retrospective investigations have utilized a variety of methodologies and definitions of "sexual experience": while some participants are asked to indicate, from a list, which sexual experiences they engaged in as a child (Haugaard, 1996; Kilpatrick, 1986; Larsson \& Svedin, 2002b; Lopez-Sanchez et al., 2002; Reynolds et al., 2003), other participants are asked to describe any sexual experience during a certain age period (Goldman \& Goldman, 1988; Lamb \& Coakley, 1993). However, despite methodological differences, these studies indicate that broadly defined sexual experiences between children are common; 42 to $94 \%$ of young adults across a wide range of studies reporting sexual experiences as a child (Goldman \& Goldman, 1988; Haugaard, 1996; Haugaard \& Tilly, 1988; Kilpatrick, 1986; Lamb \& Coakley, 1993; Larsson \& Svedin, 2002b; Lopez-Sanchez et al., 2002; Reynolds et al., 2003). When participants were asked to recall sexual experiences at young ages, however, prevalence rates drop. For example, in Reynolds et al. (2003) sample of 18- to 22-year-old college students, $24 \%$ of the males and $16 \%$ of the females recalled engaging in sexual play prior to the age of 6 . This apparent discrepancy may be due to the difficulty inherent in obtaining clear memories of early childhood.

It is clear from an examination of the extant literature that the type of informant (e.g., parent vs. daycare provider) and type of experimental design (e.g., informant vs. retrospective self-report) impacts the frequency of sexual behaviors reported. In addition, contextual factors, such as culture, may also impact the display and reported frequency of sexual behaviors, as culturally-specific values and expectations for children may influence and modify a child's behavior (Rothbaum et al., 2000). The possible role of culture has been examined in three studies, each of which compared rates of reported sexual behavior in European children to American children (Friedrich et al., 2000; Larsson et al., 2000; Schoentjes et al., 1999). Each of these studies found that behaviors that were relatively rare among the American children (e.g., inserts objects in vagina or rectum, asks to engage in sex acts), were also relatively rare among the Dutch, Swedish and Flemish children (Friedrich et al., 2000; Larsson et al., 2000; Schoentjes et al., 1999). However, there are mixed findings with regard to more common sexual behaviors. Swedish and Dutch boys and girls were reported by their parents to exhibit significantly more sexual behavior, in general, as compared to the American boys and girls. However, no significant differences were found with regard to reported sexual behaviors when a sample of Flemish children (aged 2 to 12 years) were compared to Friedrich $e t$ al's. $(1991,1998)$ samples of American children (aged 2 to 12 years; Schoentjes et al., 1999). To date, only one study has examined sexual behavior in American ethnic minority youth. Thigpen et al., (2003) found that African American parents reported fewer solitary sexual behaviors than did White parents. More research on normative and nonnormative sexual behavior in minority youth is greatly needed.

\section{Defining child sexual behavior problems}

The limited understanding of normative development discussed above has posed a challenge to adequately understanding and defining abnormal or problematic child sexual behaviors. Nonetheless, using available information on normative sexual development outlined in the previous section, researchers have attempted to summarize and describe CSBP to serve as basic guidelines for practitioners and caregivers. Building from the work of Hall et al., (1998a, 1998b) and Araji (1997), the Association for the 
Treatment of Sexual Abusers (ATSA) Children with Sexual Behavior Problems Task Force broadly defines the term as "children ages 12 and younger who initiate behaviors involving sexual body parts (i.e., genitals, anus, buttocks, or breasts) that are developmentally inappropriate or potentially harmful to themselves or others" (Chaffin et al., 2008, p. 200, italics added). Developmentally inappropriate sexual behaviors occur at a greater frequency or at a much earlier age than would be developmentally or culturally expected, become a preoccupation for the child, and/or reoccur after adult intervention/corrective efforts. Potentially harmful behaviors occur with the use of coercion, force or intimidation, cause physical injury or emotional distress in the child(ren) involved, appear to be interfering with the child(ren)'s social development, and involve children of substantially different ages or developmental levels. This definition reflects the fact that CSBP do not represent a psychological syndrome or a specific diagnosable disorder, but rather a broad continuum of behaviors (Chaffin et al., 2008). Typically, behaviors labeled as problematic include the low-frequency behaviors described in the previous section, such as attempted intercourse, oral-genital contact, and inserting objects into vagina/ rectum (Friedrich et al., 1991; Friedrich et al., 1998; Schoentjes et al., 1999). However, other more common childhood behaviors (e.g., genital touching, exhibitionism, voyeurism) may be problematic depending on the age of the child and the context in which they occur. Further, it is important to note that while the term sexual is used, the intentions and motivations for these behaviors may or may not be related to sexual gratification or sexual stimulation. The behaviors may be related to curiosity or anxiety, or may be imitative, attention-seeking or self-calming in nature (Chaffin et al., 2008; Silovsky \& Bonner, 2003). This is an important contrast to the planning and callousness sometimes involved in the behaviors of sexually abusive adults (Seto \& Barbaree, 1999).

More research, including cross-cultural work, is greatly needed in order to more fully elucidate developmental deviations outside of the normative range. Nonetheless, the operational definition provided by the ATSA Task Force provides a necessary framework, critical for practitioners and caregivers charged with the task of identifying and intervening with children exhibiting potentially problematic sexual behaviors. In addition, this definition provides a framework for researchers to examine a broad range of factors associated with the development of CBSP as well as adaptive and maladaptive trajectories of CSBP.

\section{Problems and consequences associated with child sexual be- havior problems}

Exhibiting SBP in childhood is associated with a number of problems related to adjustment and overall development. These include emotional and behavior problems (both externalizing and internalizing), skill deficits, placement disruptions, and legal interventions. These associated characteristics can be organized into two groups. First, some features may simply be mutual developmental outcomes from the same process (i.e., they may arise out of the same experience, such as maltreatment). Second, associated features might also be considered outcomes or consequences of CSBP.

\subsection{Mutual developmental outcomes}

\subsubsection{Emotional and behavioral problems}

A number of nonsexual emotional and behavioral problems have been described among children demonstrating problematic sexual behaviors. In a number of investigations, the CBCL Total Score, Externalizing Scale, and Internalizing Scale have been found to be strongly associated with CSBP (Bonner et al., 1999; Gray et al., 1997, 1999; Meyer-Bahlburg et al., 2000; Silovsky \& Niec, 2002). For example, Friedrich et al. (2001) found that greater levels of sexual behavior were strongly associated with externalizing problems for boys and girls, aged 2- to 12-years, in normative, psychiatric and sexually abused groups. For some children, it appears that SBP may be part of an overall pattern of disruptive behavior problems. Friedrich (2005) notes that this is "rather heartening," as it suggests that CSBP may not be a specialized behavioral disturbance and may be better understood by examining the larger literature on the etiology of externalizing behaviors (p. 4).

\subsubsection{Skill deficits}

Children with SBP appear to exhibit skill deficits, particularly those that are interpersonal in nature. Not surprisingly, children with sexual behavior problem often present with poor boundaries, which is often associated with socialization difficulties and stigmatizing reactions from peers (Silovsky \& Niec, 2002). Indeed, Bonner et al. (1999) found that children with SBP had more self- and parent-reported difficulties at school and lower levels of self-reported peer acceptance and self-concept than children reported to demonstrate more normative sexual behaviors. More troubling, poor interpersonal boundaries may increase risk of future victimization (Silovsky \& Niec, 2002), particularly if the child has a history of prior sexual victimization (Boney-McCoy \& Finkelhor, 1995).

\subsection{Consequences}

\subsubsection{Placement disruptions}

Children who demonstrate SBP often experience disruptions in placement, including removal from the home or changes in residential or foster care. With regard to the former, research indicates that externalizing behaviors are one of the strongest predictors of placement changes for children entering foster care (James et al., 2004; Newton et al., 2000). In fact, in a survey of foster parents, externalizing behaviors, including problematic sexual behaviors, were reported as the primary reasons they requested their foster children be placed in another home (U.S. Department of Health and Human Services, 1993). This is particularly true when there are other children in the home or if the foster parent has not received adequate training regarding child sexual behavior (Hoyle, 2000). These placement disruptions are particularly concerning for these children as extant research indicates that children who experience either volatile or multiple changes in placement are particularly vulnerable to continued internalizing and externalizing symptomatology (Newton et al., 2000).

\subsubsection{Legal system involvement}

In addition to problems related to placement disruptions, demonstration of sexual behaviors in later childhood, particularly those that at are interpersonal and intrusive in nature, may also lead to more serious consequences, such being classified as a sex offender and possible placement on public sex offender registries (Chaffin, 2008; Chaffin et al., 2008). Particularly troubling, these policies are inconsistent with available data suggesting that children with SBP pose a low long-term risk for future child sexual abuse perpetration and sexual crimes. In fact, the extant research indicates that these children are more likely to be future sexual abuse victims rather than perpetrators (Chaffin, 2008). Readers are urged to consult Chaffin (2008) for an excellent commentary on the disconnect between empirical research on children with SBP and the policies, including potential placement and legal consequences, that effect these children.

\section{Development of child sexual behavior problems}

The concepts of multifinality and equifinality are central to a developmental psychopathology framework (for a discussion, see Cicchetti \& Rogosch, 1997). Multifinality specifies that diverse outcomes are likely to develop from an initial starting point. That is, 
children sharing a single source of influence will exhibit diverse outcomes rather than the same pattern of development (Cicchetti \& Rogosch, 1997). Accordingly, the goal of multifinality is to explain how similar experiences may, across individuals, evolve into different behavioral, emotional, or psychological outcomes. For example, researchers have examined the array of biological and psychological outcomes, including problematic sexual behaviors, demonstrated by children who have experienced sexual abuse (Cicchetti \& Toth, 1995).

In contrast, equifinality specifies that a common outcome develops from different starting points, emphazing diversity in process (Cicchetti \& Toth, 1997; Cicchetti \& Rogosch, 1997). While fewer in number, some recent studies, consistent with this notion, have examined the risk factors and developmental processes associated with CSBP in both community samples and children referred for treatment for problematic sexual behaviors. This research has largely been precipitated by the finding that many children demonstrating problematic sexual behaviors do not have documented histories of sexual abuse (e.g., Silovsky \& Niec, 2002), and thus, investigators have examined multiple factors and processes that may contribute to the development of these problem behaviors. This conceptualization draws attention to the importance of studying subgroups of children who may demonstrate SBP for different constellations of reasons.

Multifinality and equifinality both suggest that the study of CSBP should occur within a broad, ecological-transactional framework (Belsky, 1993; Bronfenbrenner, 1979; Cicchetti \& Lynch, 1993) and consider risk and protective factors across multiple domains. Cicchetti and Lynch's (1993) ecological-transactional model provides a convenient and organized conceptual framework for considering the network of findings related to the development of CSBP. While originally formulated to explain the combined influence of child maltreatment and community violence on children's development, this model is applicable to the study of development more broadly (see, for example, Lynch \& Cicchetti, 1998). In this model, the ecology of child development is conceptualized as a hierarchy of co-occurring domains of influence, including contexts most distal to the child - the macrosystem (e.g., cultural beliefs) and the exosystem (e.g., neighborhood settings), and more proximal influences - the microsystem (e.g., family factors such as parenting) and the ontogenic characteristics of the child (e.g., age, temperament). Each of these domains contains both potentiating factors, which increase the probability of poor outcomes, and compensatory factors, which buffer the risk for such outcomes (Cicchetti \& Rizley, 1981). Furthermore, these factors may be transient, indicating a temporary state, or enduring, representing a more permanent state or characteristic. Whatever the type, risk factors within a level of the model can influence outcomes and processes in surrounding levels.

Our subsequent review of the literature will examine the multiple contextual influences affecting the development of problematic sexual behaviors utilizing an ecological-transactional framework. This review is split into two sections. First, studies examining the relationship between child sexual abuse and child sexual behavior problem will be examined, followed by potentiating and compensatory factors that may impact the relationship between these two variables. The relationship between child sexual abuse and problematic child sexual behaviors is given particular attention due to the historical emphasis, both theoretical and empirical, on sexual abuse as the principal cause of CSBP. Until recently, demonstration of problematic sexual behaviors was often seen as an indicator of child sexual abuse, and presently, many popular textbooks on child psychopathology include a discussion of CSBP in chapters on child sexual abuse (e.g., Mash \& Barkley, 1998; Mash \& Wolfe, 2005; for an exception, see Chaffin et al., 2002). Second, studies investigating the impact of factors across multiple ecological domains, beyond that of sexual abuse, will be examined. This review confirms the lack of a simple, unitary etiologic explanation for CSBP and highlights the dynamic interplay among and between risk factors both within and across ecological domains.

4.1. Sexual abuse as a risk factor for the development of child sexual behavior problems

Consistent with the concept of multifinality, extant research indicates that child sexual abuse (CSA) is associated with a number of emotional and behavioral problems that emerge during childhood, including posttraumatic stress symptomatology (e.g., fears, heightened startle reactions; Wells et al., 1995), depression (e.g., Ligezinska et al., 1996), self injurious behaviors (e.g., Crowe \& Bunclark, 2000), academic and behavior problems (e.g., Cohen \& Mannarino, 1998) and SBP (Cosentino et al., 1995; Friedrich et al., 2001; Kendall-Tackett et al., 1993; Mannarino \& Cohen, 1996). Reviews of the literature, however, have indicated that with the exception of posttraumatic symptoms and SBP, the majority of these symptoms characterize clinical samples in general and are not specific to sexual abuse (Kendall-Tackett et al., 1993).

Research consistently demonstrates that children who have been sexually abused engage in a higher frequency of problematic sexual behaviors than children who have not been sexually abused (Kendall-Tackett et al., 1993; Putnam, 2003). In a review of 45 empirical studies, Kendall-Tackett et al. (1993) found that sexual behaviors were the most commonly examined sequelae of child sexual abuse (examined in 23 studies). Of the eight studies that employed a comparison group comprised of either nonabused clinical or nonclinical children, all found that sexually abused children were significantly more likely to demonstrate problematic sexual behaviors than their nonabused counterparts. This relationship was also found in six of eight studies that specifically compared sexually abused children to other clinical, nonabused children; in fact, SBP and posttraumatic stress disorder symptomatology were identified as the only symptoms exhibited significantly more often by sexually abused children than by nonabused children in clinical settings. The youngest of these children (aged 3 to 5 years) were noted to have the highest prevalence of SBP (35\%).

Since the publication of Kendall-Tackett et al.'s (1993) review, studies investigating the childhood sexual sequelae of CSA have predominately utilized comparison groups comprised of samples of nonabused, nonclinical children (Hibbard \& Hartman, 1992; Inderbitzen-Pisaruk et al., 1992; Mannarino \& Cohen, 1996; Mian et al., 1996; Smith \& Howard, 1994; Stern et al., 1995; Wells et al., 1997; Young et al., 1994). Each of these studies support the robust and reliable finding that SBP are more frequently observed in sexually abused versus community samples of nonabused children. However, as Friedrich (1998) notes, at this stage of research development, these findings do little to advance the field and without the use of psychiatric control groups, it is difficult to differentiate the specific effects of sexual abuse from other childhood psychopathology. Surprisingly, only three studies since the Kendall-Tackett et al. (1993) review have employed appropriate comparison groups, all of which found significant differences in sexual behavior between the sexually abused group and nonabused psychiatric control groups. Friedrich et al. (1997) compared four groups of children (aged 7- to 11-, 12- to 14-, and 15- to 18-years): nonabused and nonpsychiatric $(n=75)$, nonabused and psychiatric $(n=165)$, suspected sexually abused and psychiatric $(n=38)$, and confirmed sexually abused and psychiatric $(n=72)$. In all age groups, the nonpsychiatric control children exhibited significantly fewer parent-reported SBP than did the three groups of clinically referred children. Further, those children with a suspected and confirmed sexual abuse history scored significantly higher on both the CSBI and Sex Problems Scale of the CBCL than did the nonabused psychiatric children.

Cosentino et al. (1995) compared 6- to 12-year-old girls with a documented sexual abuse history with two demographically comparable control groups: girls from a child psychiatry outpatient 
department and girls from a general pediatric clinic. Both the sexually abused girls and the psychiatric controls manifested more SBP and psychopathology in general compared to the nonpsychiatric controls. Further, compared to the psychiatric control group, the sexually abused girls were more likely to demonstrate problematic sexual behaviors, particularly with regard to open and excessive self-stimulation, boundary violations, and sexual aggression. These findings are consistent with Friedrich et al.'s (1987 and 1988) examination of sexually abused girls, nonabused psychiatric girls, and nonabused nonpsychiatric girls.

Finally, Friedrich et al. (2001) compared mother-reported child sexual behaviors in three samples of children, aged 2 to 12 years: a nonabused, nonclinical sample $(n=1114)$, a nonabused, clinical psychiatric outpatient sample $(n=577)$, and a sample of children with substantiated sexual abuse histories $(n=620)$. Sexual behaviors, particularly behaviors relating to poor personal boundaries and sexual knowledge and interest, were reported significantly more often by mothers of children in the psychiatric outpatient group than mothers of the nonabused, nonclinical children. However, all problematic sexual behaviors were reported to be displayed by the sexually abused children more often than either the psychiatric outpatients or the nonclinical group. This relationship was found not only in the total sample, but also when specific age groups (2- to 5-, 6- to 9-, and 10- to 12-year-old boys and girls) were examined.

Consistent with the concept of equifinality, another body of research has examined sexual abuse histories of children referred for treatment for SBP, as opposed to examining SBP in samples of children referred due to sexual abuse. This research indicates that prior sexual abuse is often present in the histories of these children; however, it is also evident that this history is not always present, even in the children displaying the most intrusive behaviors. Bonner et al. (1999) compared 201 children (6- to 11-years-old) identified as having SBP to 52 demographically-matched children with no reported SBP. While children with SBP had significantly higher rates of sexual abuse histories than children in the comparison group, more than half the children in both groups did not have a substantiated history of sexual abuse. Further, in a sample of 127 children aged 6 to 12 years referred for treatment for problematic sexual behaviors, Gray et al. (1997) found rates of motherreported prior sexual abuse varied from $93 \%$ for females to $78 \%$ for males. However, it is important to note that these rates were provided by mothers of the children, as opposed to cases substantiated by social service agencies.

Compared to school-aged children, lower rates of sexual abuse have been in found in samples of preschool-aged children. For example, in a sample of 37 children (age 3 to 7 years) referred by Child Protective Services and mental health clinics to a SBP-specific treatment program, $38 \%$ had a history of substantiated sexual abuse. In other words, the majority of the children (62\%) did not have a history of substantiated sexual abuse, but nonetheless displayed a high frequency and severity of SBP. However, it is important to note that suspected sexual abuse was investigated in $76 \%$ of the cases. Thus, it is unclear whether the low incidence of substantiated sexual abuse is a product of the general difficulty substantiating sexual abuse in young children or is an accurate reflection of the abuse rate. Whichever the case, the fact that sexual abuse is not an experience always found in the histories of children with SBP cannot be ignored (Friedrich, 2007).

\subsubsection{Risk factors for sexual behavior problems in samples of sexually abused children}

The research reviewed above indicates that sexually abused children are more likely to demonstrate problematic sexual behaviors than are nonabused children from either community settings or psychiatric settings. It is also clear, though, that many children who have been sexually abused do not develop SBP, and likewise, many children with SBP have no known history of CSA. Given the consistency of the results of studies in this area, some researchers have moved beyond an examination of whether sexually abused children are at risk for developing problematic sexual behaviors and have begun to identify factors that account for this association. While limited, this research is critical in helping to explain why some children who have been sexually abused develop psychopathology, including CSBP, whereas others are able to achieve a more adaptive level of functioning.

4.1.1.1. Abuse-specific factors A number of studies have examined the influence of abuse characteristics that may mediate the relationship of CSA and CSBP (Cosentino et al., 1995; Friedrich et al., 1992, 2001, 2003). For example, Cosentino et al. (1995) found that sexual abuse perpetrated by fathers or stepfathers and that involved vaginal and/or anal penetration was associated with particularly marked sexual behavior disturbances, including the most sexually aggressive behaviors. Similarly, Friedrich et al. (2001 and 2003) found that more problematic sexual behavior was reported in children who were penetrated (orally, vaginally, or anally) by a family member or had multiple perpetrators, and who were abused frequently and over a longer duration. These associations are consistent with those found by Friedrich et al. (1992) previous examination of the CSBI, with the exception of relationship to the perpetrator, which was not assessed. There are mixed findings with regard to the use of force or sadism (Friedrich et al., 1992, 2001; Hall et al., 1998a, 1998b).

These and other (e.g., Friedrich et al., 1986) studies indicate that relationship to the perpetrator appears to be an important factor, with a closer relationship usually associated with increased risk of developing problematic sexual behaviors, as well as greater psychopathology in general (Friedrich et al., 1992, 2001; Kendall-Tackett et al., 1993; Noll et al., 2003; Trickett et al., 2001). It is important to note that relationship to the perpetrator is confounded with age of onset, duration of abuse, and the use of physical force. For example, biological father-daughter incest is associated with much earlier onsets, and longer durations of abuse, but with less use of physical force (Mennen and Meadow, 1995; Trickett et al., 1997).

4.1.1.2. Risk factors at the ontogenic level Developmental psychopathology, including ecological-transactional models (Cicchetti \& Lynch, 1993), acknowledges that children are not simply blank slates shaped by outside forces (such as the experience of sexual abuse) but rather actors continuously affecting and being affected by their environment (Bronfenbrenner, 1979). Recent research has also examined a number of factors, beyond that of abuse characteristics, which may also impact the relationship between victimization and subsequent CSBP.

Child age has been the most widely investigated ontogenic factor relevant to the development of problematic sexual behavior following CSA. As noted earlier, in their review of the literature, Kendall-Tackett et al. (1993) reported that SBP were most prevalent in the youngest age group of children (aged 3 to 5 years) with a history of child sexual abuse. This finding is consistent with other studies; for example, McClellan et al. (1996) found that onset of sexual abuse at an early age, particularly between ages 0 and 3 years, was the strongest predictor of all types of problematic sexual behaviors in a sample of both boys and girls. This trend is consistent with research on normative behaviors discussed earlier, indicating that younger children are more likely to be reported to engage in both normative and nonnormative sexual behaviors than are older children.

It is not clear how child gender impacts the development of CSBP following CSA. While literature on gender differences in the manifestation of behavior problems suggests girls are more likely to experience internalizing problems than are boys (e.g., Cutler \& Nolen-Hoeksema, 1991), the findings for sexually abused samples are inconsistent (Friedrich et al., 1986; Kolko et al., 1988; Livings- 
ton, 1987; Tong et al., 1987). This maybe in part, due to the fact that majority of studies to date have not examined boys and girls in the same study, making comparisons difficult (Feiring et al., 1998). Nonetheless, sexually abused girls may be more likely than boys to exhibit more PTSD symptoms following CSA (Friedrich, 1998; Wolfe et al., 1991), including sexual anxiety (the feeling that sex is dirty) (Feiring et al., 1998). More research on the role of gender in the display of sexual behavior problems specifically is needed.

In addition to child age and gender, the larger literature on socioemotional and behavior outcomes following child sexual abuse has examined the mediational role of a number of other child factors, including physiological regulation (e.g., De Bellis, Lefter, Trickett, \& Putnam, 1994), affect differentiation and regulation (e.. g, Rieder \& Cicchetti, 1989), coping style (e.g., Spaccarelli, 1994), attachment style (e.g., Toth \& Cicchetti, 1996), locus of control, and history of previous trauma and preexisting psychopathology, such as depressive symptomatology (e.g., Toth \& Cicchetti, 1996). However, only two studies have examined the role of child characteristics, beyond that of age, impacting the relationship between CSA and CSBP, specifically. In a sample of 100 sexually abused boys and girls, Hall, et al. (1998b) found blame attributions (i.e., who the child blames for the abuse) significantly differentiated between three groups of children: children demonstrating developmentally expected sexual behaviors tended to blame the perpetrator for the abuse, those exhibiting problematic intrapersonal sexual behaviors were primarily self-blaming, and those demonstrating problematic interpersonal sexual behaviors were primarily more ambivalent. Similarly, Mannarino et al. (1994) found that decreases in reported CSBP were related to more appropriate blame attributions. Finally, it is important for future work to examine the mediational role of temperament in the development of CSBP following CSA. Temperament has been implicated in the etiology and maintenance of almost every form of child psychopathology (Rothbart and Bates, 2006; Thomas and Chess, 1977), and while some have speculated that temperament may play a role in childhood outcomes following CSA (Mannarino \& Cohen, 1990), to our knowledge this has yet to be investigated empirically.

4.1.1.3. Risk factors in the microsystem Studies examining the role of the microsystem have predominately focused on factors related to family circumstances/environment. Family dysfunction not only may increase the likelihood of sexual abuse, particularly intrafamilial, but also may exacerbate the effects of abuse once it has occurred (Alexander, 1992). Studies examining the influence of parenting practices have found that one of the best predictors of child outcome, broadly defined, is the response of the child's non-offending caregiver(s) following the sexual abuse (Cohen \& Mannarino, 2000; Everson et al., 1989; Finkelhor \& Kendall-Tackett, 1997). Specifically, studies have investigated the role of parental social support on the development of SBP following child sexual abuse. In a sample of sexually abused girls (Leifer et al., 1993), as well as a sample of both sexually abused girls and boys (Everson et al., 1989), low maternal support was associated with the display of significantly greater problematic child sexual behaviors. Hall et al. (2002) found that children demonstrating the most severe SBP (those that were interpersonal in nature, planned, and coercive) received significantly less maternal support than those children demonstrating self-focused or developmentally expected sexual behaviors. Further, several studies have found that the highest risk of failure to support is found when the offender is a live-in boyfriend or husband (Everson et al., 1989; Elliot \& Briere, 1994). In contrast, however, Mannarino and Cohen (1996) did not find any relationship between maternal support and SBP, or any other symptomatic behaviors in their sample of sexually abused girls, aged 7 to 12 years old. One possible explanation for this discrepancy may be that these authors measured the mother's perceptions of her level of support via paper and pencil self-report measures, in contrast to Leifer et al. (1993) and Everson et al. (1989) measurement of maternal support via clinical interviews. The effect of parent social support on child functioning following sexual abuse has been hypothesized to vary as a function of age; specifically, caregiver response to younger children may be more influential than it is for older children, who may have additional opportunities for social support from peers or other adults (Finkelhor \& Kendall-Tackett, 1997).

Furthermore, Mannarino and Cohen (1996) found that, in their sample of 7- to 12-year-old sexually abused girls $(n=77)$, intensity of parental emotional reaction to the abuse was positively related to child internalizing and externalizing symptomatology, including parent-reported CSBP, as measured by the CSBI. The authors speculate that this may be due to the possibility that parents who demonstrate strong emotional reactions to the abuse may be able to less effectively parent. On the other hand, SBP may arise if a child perceives that his/her parent is troubled by the abuse disclosure. This may be particularly true if the child blames themselves for the abuse (e.g., Hall et al. 1998b), suggesting that the interaction of child and parent characteristics may provide a more complete picture of the development of SBP following CSA than either domain alone.

On the other hand, several characteristics of the family environment have been demonstrated to serve as compensatory factors, buffering against the development of SBP following CSA. Using the same sample as Hall et al. (1998a, 1998b), Hall et al. (2002) found that the sexually abused children who failed to demonstrate SBP were significantly more likely than their counterparts exhibiting SBP to come from a more functional family (marked by stability, support, problem-solving, etc.) with more functional caregivers, have a stronger parent-child relationship, and a less sexualized home environment. It is important to note, however, that all variables were coded from files; prospective research utilizing self-report measures and/or interviews would engender greater confidence in these findings.

Research has focused on the impact of maternal psychological and emotional functioning on the relationship between CSA and CSBP. While not widely examined, there is good reason to believe that maternal psychopathology would have a negative impact on the development of CSBP in children who have been sexually abused. Parental psychopathology, including depression, posttraumatic stress symptomatology, substance abuse and emotional distress, have been shown to serve as predictive factors of various negative outcomes of sexually abused children, such as attentiondeficit/hyperactivity disorder (ADHD), conduct disorder (CD), posttraumatic stress disorder (PTSD), and other behavior problems (Cohen \& Mannarino, 1996; Manion et al., 1998; Paredes et al., 2001). With regard to CSBP specifically, research has only investigated the role of maternal PTSD and emotional distress as potential moderators and/or mediators of the effect of CSA. For example, Paredas et al. (2001) found that in a sample of sexually abused children (aged 6 to 13 years) and their mothers $(n=67)$, maternal-reported trauma symptomatology was associated with maternal-reported CSBP. In Hall et al.'s (2002) sample, greater than 70\% and approximately $40 \%$ of the mothers of children demonstrating problematic interpersonal sexual behaviors and problematic selffocused sexual behaviors, respectively, were rated to have a high degree of posttraumatic stress symptomatology.

Consistent with Eckenrode et al.'s (1993) contention that adversity is not randomly distributed, other maltreatment experiences have been found in the histories of sexually abused children demonstrating SBP. In a sample of sexually abused children (aged 3 to 7 years), children demonstrating interpersonal problematic sexual behaviors (defined by the authors as "sexual contact/touch with others") were significantly more likely than children demonstrating more normative sexual behaviors to have histories of physical and emotional abuse (Hall et al. 1998a, 1998b) and to have been exposed to domestic violence and sexualized interactions in the home (Hall et al., 2002). 
One study has examined the impact of family adversity on the development of CSBP subsequent to CSA. Friedrich et al. (1992) found that family socioeconomic status was a significant predictor of SBP for older (age 7 to 12 years), but not younger (age 2 to 6 years) sexually abused girls.

4.1.1.4. Risk factors in the exosystem and mesosystem Consistent with the principle of multifinality, it appears that the impact of sexual abuse on the display of sexual behaviors varies across children and depends on a number of contextual factors across several ecological domains. However, factors in the exosystem and mesosystem have yet to be examined as possible mediators of CSA and CSBP. Although these contexts may be less proximal, extant research indicates that exosystem-level factors, including exposure to community violence and poverty, can serve as enduring vulnerability factors that can both increase risk for abuse (Cicchetti \& Lynch, 1993) and have detrimental effects on children's socioemotional development and health (Jenkins \& Bell, 1997). These factors are important to examine in future work.

\subsection{Factors beyond child sexual abuse associated with the development of child sexual behavior problems}

As noted above, not all children with SBP have a history of CSA (Bonner et al., 1999; Gray et al., 1997; Silovsky \& Niec, 2002). This finding highlights the importance of investigating the contribution of other variables to the emergence of CSBP (Friedrich \& Trane, 2002; Larsson \& Svedin, 2002a). Empirical studies that have attempted to do so have typically been approached in one of two ways: either examining samples of children referred for treatment for problematic sexual behaviors, or by examining problematic sexual behaviors in more heterogeneous samples of community children. Regardless of approach, this research, consistent with the concept of equifinality, highlights the diversity in processes involved in the development of CSBP. Risk factors in the various ecological domains will be discussed below.

\subsubsection{Risk factors at the ontogenic level}

As noted above, ontogenic factors are child characteristics that alone, or by interacting with environmental circumstances, contribute to the development of CSBP. Ontogenic factors investigated with regard to the development of CSBP include gender, age and biological factors. The broader literature on child psychopathology suggests that temperament and cognitive functioning may be particularly fruitful area for future investigation.

4.2.1.1. Gender In general, boys are more likely to be referred for intervention for SBP than are girls (Bonner et al., 1999; Carpentier et al., 2006; Gray et al., 1999; Ray \& English, 1995). One notable exception, however, is Silovsky and Niec's (2002) sample of preschool children in which $65 \%$ of the children referred for treatment were girls.

The literature, however, does not show pervasive gender differences in reported problematic sexual behaviors in samples of children from the community. Nearly all studies, many of which were described previously, find the more low-frequency, problematic sexual behaviors to occur at similar rates for both boys and girls (Friedrich et al., 1991, 1998, 2000; Lindblad et al., 1995; Schoentjes et al., 1999). For example, in a sample of children without reported sexual abuse histories $(n=690)$, boys and girls were reported to demonstrate similar prevalence rates of sexual behaviors (Merrick et al., 2008). Similarly, in a community sample of children aged 6 to 10 years, boys and girls were reported by their parents to engage in similar rates of SBP (Meyer-Bahlburg et al., 2000). Finally, in a large sample $(n=2311)$ of children, gender was not related to the prevalence and type of reported sexually intrusive behavior (Friedrich et al., 2001). However, some research suggests that gen- der effects may vary depending on placement in alternate care. In a sample of children in kinship and foster care, Tarren-Sweeney (2008) found girls were more likely to be reported to exhibit problematic sexual behavior, as measured by a caregiver-report psychiatric rating scale, even after controlling for sexual abuse.

4.2.1.2. Age In general, the extant literature indicates that CSBP are correlated inversely with age (Friedrich et al., 2003; Gray et al., 1997; Letourneau et al., 2004). As noted earlier, this trend has also been found when normative sexual behaviors are examined, as well as when problematic sexual behaviors are examined in samples of sexually abused children. Several studies utilizing referred and/or community samples support this relationship (Friedrich et al., 2003; Gray et al., 1997). Even more sexually intrusive behaviors have been found to be more prevalent among younger versus older children (Friedrich et al., 2003).

Some researchers have suggested that this inverse relationship suggests that, at least to some degree, SBP are due to immaturity (Friedrich et al., 2003). Nonetheless, it is also plausible that these prevalence figures, all determined via parent report, underestimate the actual incidence of problematic sexual behaviors in older age groups. As noted earlier, some parents may have limited opportunity to observe their child engage in sexual behaviors (Larsson \& Svedin, 2002a), particularly those that may involve other children. Older children may exercise more restraint and conceal these behaviors from adult view (Bancroft et al., 2003).

4.2.1.3. Biological factors Unfortunately, beyond age and gender, we know very little about individual factors contributing to the development of SBP. Studies that have, however, have examined genetic factors and cognitive functioning. Långström et al. (2002) examined the relative importance of genetic and environmental factors for problematic masturbatory behavior in a sample of 1106 Swedish monozygotic and dizygotic twins, aged 7 to 9 years. While there was a low base-rate of problematic masturbatory behavior, as assessed by two items on the CBCL, the genetic effect on these behaviors was substantial and accounted for $77 \%$ of the variation. Significant, but small contributions to variance in public or excessive masturbatory behavior were caused by shared environmental factors $(10 \%)$ and nonshared environmental factors $(13 \%)$. The latter finding indicates that family sexuality (e.g., child exposure to nudity) did not strongly affect twin similarity in the display of problematic masturbatory behaviors. This study has strong implications for the study of individual differences which have been shown to be of great importance in existing theories of child problem behavior (e.g., Frick \& Morris, 2004).

There is mixed research regarding the cognitive functioning of children with SBP. Silovsky and Niec (2002) found that in their sample of preschoolers exhibiting extreme problematic sexual behavior, receptive language capabilities fell in the low average range. On the other hand, the cognitive functioning of a sample of 6- to 11-year-old children with SBP was comparable to that of a demographically-matched comparison group (Bonner et al., 1999). The role of cognitive functioning deserves further empirical attention. A number of longitudinal studies have found low cognitive abilities, particularly those that are verbal, to be predictive of childhood maladjustment and behavior problems (Moffitt, 1993).

While not yet examined in the context of CSBP, temperament has been shown to play a role in the etiology and maintenance of psychopathology in both children and adults (Rothbart and Bates, 2006; Thomas and Chess, 1977). It appears that temperament may constitute a vulnerability that is actualized, along with other potential developmental risk factors, in the context of environmental situations (Patterson et al., 2000; Sanson \& Prior, 1999), which may include maltreatment or other traumatic experiences, or the family or neighborhood environment. 
4.2.2. Risk factors in the microsystem As noted earlier, the microsystem refers to the immediate environment, such as the child's family or school. Similar to the research reviewed on the development of SBP in children with histories of sexual abuse, family environment/circumstances have received the most empirical attention in studies approached from a perspective consistent with equifinality. These factors include maltreatment, parenting, family circumstances, and family sexuality.

4.2.2.1. Maltreatment Extant research indicates that child maltreatment, including and beyond that of sexual abuse, is a significant factor in the development of CSBP. In fact, research indicates that nearly all children referred for treatment for problematic sexual behaviors are victims of some form of maltreatment (Bonner et al., 1999; Gray et al., 1997; Silovsky \& Niec, 2002). As reviewed above, sexual abuse histories are common among children referred for treatment. However, other types of maltreatment, including physical abuse, emotional abuse, neglect and exposure to domestic violence, appear to be common as well. With regard to physical abuse, studies report prevalence rates ranging from $32 \%$ for substantiated CPS reports to $48 \%$ for parent report (Bonner et al., 1999; Gray et al., 1999; Silovsky \& Niec, 2002). Similarly, rates of neglect and emotional abuse in children referred for SBP range from 16\% to $18 \%$ and $29 \%$ to $39 \%$, respectively, for CPS and parent reports (Bonner et al., 1999; Gray et al., 1997).

Exposure to domestic violence has received less empirical attention. However, at least two studies indicate that interparental violence is common in the both the families of young children demonstrating problematic sexual behaviors (Silovsky \& Niec, 2002), and children exhibiting sexually intrusive behaviors specifically (Friedrich et al., 2002). In fact, in Silovsky and Niec (2002) sample of preschool children with SBP, rates of both physical abuse and domestic violence exposure were greater than that of sexual abuse.

Consistent with research indicating there is substantial overlap in maltreatment types (U.S. Department of Health and Human Services, 2005), many children exhibiting SBP experience multiple forms of maltreatment. For example, 52\% of the 6- to 9-year-olds and $63 \%$ of the 10 - to 12-year-olds in Gray et al.'s (1997) study were victims of several forms of abuse, with the most frequent combination being sexual abuse and physical abuse. This is consistent with the accumulation of risk model (Rutter, 1989), which holds that almost all children are capable of coping with low levels of risk until the accumulation exceeds a developmentally determined threshold, or the risks outweigh the buffer provided by compensatory factors (Sameroff et al., 1993). Along these lines, some research indicates that children entering foster care at later ages are significantly more likely to exhibit SBP than their younger counterparts (Tarren-Sweeney, 2008). For maltreated children, this provides an approximation of their length of exposure to adversity and accumulation of risk.

Nonetheless, because of the high co-occurrence in maltreatment experiences, it is difficult to determine the relative contribution of maltreatment type to the development of CSBP. It is also unclear the extent to which the severity, age of onset, chronicity and recency of various maltreatment experiences influence the development of problematic sexual behaviors. Merrick et al. (2008) attempted to address these issues by examining the timing and impact of physical abuse, neglect, and emotional abuse on sexualized behaviors in a prospective study of high-risk children (all 8-yearsold) without a sexual abuse allegation $(n=690)$. Instead of relying on substantiated reports (which likely underestimates the actual incidence of maltreatment), maltreatment allegations were used, which may more accurately capture the actual maltreatment experiences of children (e.g., Drake, 1996; Leiter \& Myers, 1994). Both early (before age 4 years) and late (between age 4 and 8 years) reports of physical abuse consistently increased the odds of both boys and girls engaging in problematic sexual behaviors. The pattern differed by gender, however, with physical abuse predicting sexual in- trusiveness and exhibitionism in boys and boundary problems (e.g., hugging adults they don't know well) in girls. On the other hand, early reports of neglect and emotional abuse were associated with significantly fewer sexualized behaviors in boys, whereas girls with early reports of emotional abuse were more likely to evidence inappropriate sexual knowledge than their counterparts. These findings concerning neglect and emotional abuse are consistent with Bonner et al.'s (1999) finding that children with SBP were significantly older than their counterparts displaying normative sexual behavior when both emotional abuse and neglect reportedly occurred.

4.2.2.2. Stressful familial and life events Limited research has investigated the role of stressful familial events, beyond that of maltreatment, in the development of CSBP. Those that have, however, indicate that children with SBP are more likely than their normative and psychiatric counterparts to have experienced stressful life events (Friedrich et al., 1991, 1992, 2001). This is consistent with the finding that life stress in children is associated with many psychosocial and behavioral problems (Compas, 1987). For example, in a sample of Finnish children, an increase in all types of sexual behaviors was found for both boys and girls who had at least one life stressor present in their lives (Santtila et al., 2005). Similarly, in Friedrich et al.'s (2001) large sample of normative, psychiatric, and sexually abused children, life stress intensity (defined as the total number of life events experienced by the child, except for sexual abuse, divided by the child's age in years) was directly related to SBP across all ages and genders.

Furthermore, Bonner et al. (1999) found that children demonstrating SBP were more likely than their at-risk counterparts to have experienced parental divorce and/or a death in the immediate family. Further, a substantial portion (43\%) of the preschool children in Silovsky and Niec's (2002) sample were in foster care. However, as noted earlier, the direction of the association between SBP and foster care is unclear. Children may be removed from their families and placed in foster care due to the display of problematic sexual behaviors. On the other hand, removal from the home due to maltreatment often serves as a source of stress and disruption (Melton, 1990), which in turn, may serve as a potentiating factor for the development of CSBP. Along these lines, research indicates that among children in kinship or foster care, placement instability is related to an increased likelihood of reported CSBP (Tarren-Sweeney, 2008).

4.2.2.3. Parenting Broadly defined, parenting practices have been consistently linked with children's developmental outcomes and well-being (Collins et al., 2000). Coercive (e.g., Patterson, 1982, 2002) and rejecting (e.g., Rothbaum \& Weisz, 1994) parenting, poor monitoring (e.g., Loeber \& Stouthamer-Loeber, 1986), and violent discipline (e.g., Strassberg, Dodge, Pettit, \& Bates, 1994) have all been linked to the development of child externalizing behaviors. On the other hand, extant research indicates that regardless of ethnic and socioeconomic status, positive parental involvement and the provision of structure (e.g., limits) are associated with healthy child development (e.g. Patterson, 1982). Unfortunately, very little research has examined these factors with regarding to the development of CSBP. The research that has, however, indicates that parents of children exhibiting SBP are more likely than other parents to view their children as excessively demanding of their attention and time, view interactions with their child as unrewarding, and be more emotionally distant from their children (Pithers et al., 1998). Furthermore, the parent-child relationship is more likely to be dominated by conflict (Pithers et al., 1998). These characteristics may result in decreased parental monitoring and support. Furthermore, in Gray et al.'s (1999) sample of 6- to 12-year-old children referred for treatment for SBP, modeling of socially maladaptive behaviors extended beyond that of family violence. At least one parent had a history of arrest in $35 \%$ of the families and $45 \%$ of the families contained at least one perpetrator of sexual abuse. 
Child sexual behavior problems are consistently associated with early, age-inappropriate exposure to sexual behavior or knowledge (Bonner et al., 1999; Friedrich et al., 1991, 1992, 2003). Friedrich et al. (1991, 1992, 2001) samples, parents who endorsed family sexuality, which includes items related to nudity, opportunities to witness sexual intercourse and look at pornographic magazines/movies, co-sleeping, and co-bathing, also reported higher levels of sexual behavior in their children, regardless of whether the child had a history of sexual abuse. Furthermore, modeling of sexuality (consisting of both family sexuality and sexual abuse) has been found to be significant predictor of sexually intrusive behavior specifically (Friedrich et al., 2003).

4.2.2.4. Family circumstances Children from impoverished families are at a considerably increased risk for a number of adverse experiences and outcomes, including, for example, maltreatment (Pelton, 1994), aggression (Loeber \& Dishion, 1983), and school failure (O'Donnell et al., 1995). Along these lines, approximately half of the families in Gray et al. $(1997,1999)$ samples were living at or below the poverty line, and Friedrich et al. (2003) found family adversity (as measured by family income) to be one of the strongest predictors of sexually intrusive behaviors, above and beyond that of sexual abuse. Of course, poverty is confounded with a number of other familial risk factors, including stressful life events and parenting. Nonetheless, it will be important for future research to examine the role of stress caused by fiscal disadvantage, particularly at differing developmental time points. For example, statistics indicate that the children at greatest risk for maladaptive outcomes are those who are young at the time of exposure to economic hardship and/or experience severe and chronic hardship (Lynch et al., 1997).

\subsubsection{Risk factors in the exosystem and mesosystem}

There has been a paucity of research examining the relationship between exosystem and mesosystem level factors and CSBP in samples of children referred for treatment and more normative or at-risk samples. Promising areas for future work include the influence of daycare, school, and larger neighborhood and community.

4.2.3.1. Daycare and school Some research indicates that hours per week in daycare is related to an increase in parent-reported child self-stimulatory behavior, exhibitionism, boundary problems, sexual intrusiveness, and voyeuristic behavior, suggesting that this setting may provide opportunities for social learning (Friedrich \& Trane, 2002). The school setting, however, has yet to receive empirical attention. This is surprising, as outside the immediate family, school has been identified as having one of the largest impacts on child development (Cicchetti \& Toth, 1997). Exposure to violence at school, whether as a witness or victim, is related to a number of emotional and behavioral problems (Schwab-Stone et al., 1995). On the other hand, school may serve as a buffer of the effects of the many psychosocial stressors present in the lives of children with SBP (e.g., Rutter, 1979). Along these lines, the setting in which sexual behavior is displayed is a particularly important area for research. Studies of normative child sexual behavior indicate that children are less likely to be reported engaging in sexual behaviors at daycare than they are at home (Larsson \& Svedin, 2002a). It is unclear whether this is due to the informant (daycare provider versus parent), or the nature of the setting, which may impact behavioral or emotional control.

4.2.3.2. Community and culture The larger communities in which children and their families live also constitute important factors; communities may provide support to parents in being effective caregivers to their children (Bronfenbrenner, 1979). Violent communities, as well as those with a large number of single-parent households and a high degree of neighborhood child care burden have all been implicated in poor child outcomes, including maltreatment (Garbarino \& Sherman, 1980). There is also evidence that community-level factors, when paired with microsystem factors, are associated with especially poor outcomes. For example, Lynch and Cicchetti (1998) found that when paired with child maltreatment, community violence was associated with a significantly greater risk for child problems such as depression, deficits in self-esteem, and traumatic stress.

Finally, the impact of culture, a mesosystem-level factor, on the development of CSBP has yet to receive empirical attention. As noted earlier, culturally-specific principles and expectations for children may both influence and modify children's behavior (Rothbaum et al., 2000). It is unclear the extent to which SBP vary across nations, or across ethnic, racial or cultural groups within nations.

\section{Conclusion and implications}

The current review is the first attempt to date to synthesize the various empirical literatures on the development of CSBP within a developmental psychopathology framework. While growing, it is clear that the literature on childhood sexual behavior, both normative and problematic, is in its infancy. Nonetheless, research indicates that the display of certain sexual behaviors in childhood are expected and appropriate (Friedrich et al., 1991, 1992, 2001; Larsson \& Svedin, 2002a; Lindblad et al., 1995; Sandfort \& Cohen-Kettenis, 2000), whereas others are more problematic, or "developmentally inappropriate or potentially harmful to themselves or others" (Chaffin et al., 2008, p. 200). It is clear that children with SBP are a complex, heterogeneous group, more so than adolescents with SBP and adult sexual offenders (Chaffin et al., 2002). This heterogeneity is apparent in samples of children who have been sexually abused, referred for treatment for CSBP, and recruited from the community.

Although sexually abused children are observed engaging in more problematic sexual behaviors than their normative or psychiatric counterparts, it is clear that such behaviors may be the result of factors other than sexual abuse (e.g., Merrick et al., 2008). Our review confirms the lack of a simple explanation for CSBP and highlights the need for research to examine the dynamic relationships among risk factors both within and across ecological domains. Below we present several suggestions for future empirical work, including increased research on normative child sexual behavior, and the need for research to employ longitudinal designs, examine specific developmental stages, and investigate multiple ecological domains, including meso- and exosystem-level factors, in concert.

It is essential that future work examine normative, in addition to problematic child sexual behavior. As discussed, maladaptive behavior must be viewed in relation to what is considered normative behavior for a given developmental time point (Cicchetti \& Sroufe, 2000). Great strides have been made in the last decade concerning what should be considered normative, predominately due to large samples (Friedrich et al., 1992, 2001) of sexually abused, psychiatric, and normative children, and Scandinavian samples of community children (Friedrich et al., 2000; Larsson et al., 2000; Schoentjes et al., 1999). Nonetheless, there is still a lack of consensus on what is considered normative sexual behavior at different points in a child's life. Extension and replication of Friedrich and colleagues' important studies would help to more precisely identify those behaviors that are normative and in which environments (i.e., school, home). The distinction between normative and nonnormative sexual behaviors can have serious consequences. This distinction informs not only whether intervention is necessary, but whether behaviors involving more than one child necessitate reporting to child protective services agencies or possible legal intervention (Chaffin et al., 2008).

To date, researchers have tended to study children with SBP in broad age ranges such that two or more distinct developmental stages are included (e.g., Letourneau, Schoenwald \& Sheidow, 
2004) whereby confounding any developmentally relevant information. Future work should examine more specific age groups (see, for example, Friedrich et al., 2003; Schoentjes et al., 1999). Furthermore, it is also important to consider the timing of various risk factors (e.g., maltreatment) with respect to age (see, for example, Merrick et al., 2008). In other words, research must be sensitive to the normative maturational tasks that the child is attempting to master at the time of exposure to the risk factor.

Empirical attention must also be given to following children across developmental transitions. Demands change drastically across various developmental periods, and may differentially interact with other characteristics in the child's ecology (Friedrich, 1998). This is also important when examining protective factors that may help children develop more healthy and normative sexual behaviors after demonstrating SBP in a certain period. That is, for which children will early CSBP be a transient developmental phenomenon, and for which will early SBP be an indicator of persistent maladjustment? It is clear that the majority of children with SBP do not continue to demonstrate problematic sexual behaviors, including sexual offending, into adolescence and adulthood (Carpentier et al., 2006; Letourneau et al., 2008).

While the majority of the extant research on CSBP utilizes cross-sectional designs (for an exception, see Merrick et al., 2008), questions of both etiology and course are best examined in prospective, longitudinal research designs. Such designs should utilize multiple informants and examine diverse groups of children in terms of geographic location, race and ethnicity, and socioeconomic status. Furthermore, person-centered approaches may be particularly advantageous for describing unique pathways to sexual behavior problems among discrete subgroups of children. Most research, on CSBP and other forms of child psychopathology, has used a variable-centered approach in which risk factors are related to outcomes. However, a variable-oriented approach to child sexual behavior problems may tend to overlook subgroups of children who may exhibit sexual behavior problems as a result of processes that are less typical. In contrast, person-centered approaches view individuals as "organized wholes" (Bergman \& Magnusson, 1997, p. 291) and search for groups of individuals characterized by patterns of association among variables that are similar within groups and different between groups (Laursen \& Hoff, 2006).

Although still nascent, research examining the complex relationship between ecological domains and the development of CSBP is beginning to explain some of the heterogeneity in both process (e.g., equifinality) and outcome (e.g., multifinality). The majority of studies in this area have focused on the mesosystem and the impact of both abuse and children's immediate family environment. Given the proximal nature of the family and the importance of the caregiving process on children's development, this tendency is not unexpected. However, the relative paucity of research examining factors at the ontogenic level is surprising. For example, gender, temperament and cognitive functioning are likely critical in understanding the development and persistence of CSBP given the implication of these factors in various forms of child psychopathology (Rothbart \& Bates, 2006). Furthermore, there is a crucial need for more research on the impact of peer groups, schools and neighborhoods in the development of CSBP. Although these contexts may be less proximal, extant research indicates that exosystem-level factors, particularly exposure to community violence, may serve as enduring vulnerability factors (Cicchetti \& Lynch, 1993).

Presently, the ATSA definition of CSBP emphasizes the role of culture, noting that developmentally inappropriate sexual behaviors occur at a greater frequency than would be culturally expected (Chaffin et al., 2008). However, we know very little about the influence of culture on child sexual behaviors, both normative and particularly problematic. The milieu in which a child develops (including cultural norms, practices, and beliefs) is likely to influence developmental course (Garcia Coll et al., 2000) and the dynamic interplay of risk and protective factors.

Our overarching goal in this article was to elucidate those aspects of developmental psychopathology that are integral toward understanding the development of CSBP. In so doing, the current review aimed to provide a framework that will help stimulate future empirical research that can help inform both intervention and prevention efforts. It is imperative that future research utilize prospective, longitudinal designs that can adequately capture developmental differences. This should include examinations of not only differences between children in different age groups, but the persistence and desistance of such behaviors within individual children. The context in which children develop and display problematic sexual behaviors must also be considered. Finally, it is crucial that research examine the more normative aspects of child sexual behavior. This research can help to aid in the distinction between normative and nonnormative, a distinction that can inform both clinical and possible legal intervention.

\section{References}

Achenbach, 1990 T. Achenbach, Conceptualization of developmental psychopathology. In: M. Lewis and S. Miller, Editors, Handbook of developmental psychopathology, Plenum Press, New York (1990), pp. 3-27.

Achenbach, 1991 T. M. Achenbach, Manual for Child Behavior Checklist/ 4-18 and 1991 Profile, University of Vermont, Department of Psychiatry, Burlington, VT (1991).

Alexander, 1992 P. C. Alexander, Application of attachment theory to the study of sexual abuse, Journal of Consulting and Clinical Psychology 60 (1992), pp. 185-195.

Araji, $1997 \longrightarrow$ S. K. Araji, Sexually aggressive children: Coming to understand them, Sage, Thousand Oaks, CA (1997).

Bancroft, 2003 In: J. Bancroft, Editor, Sexual development in childhood, Indiana University Press, Indiana (2003).

Bancroft et al., 2003 J. Bancroft, M. A. Reynolds and D. L. Herbenick, Masturbation as a marker of sexual development: Two studies 50 years apart. In: J. Bancroft, Editor, Sexual development in childhood, Indiana University Press, Bloomington (2003).

Belsky, 1993 J. Belsky, The etiology of child maltreatment: A developmental-ecological analysis, Psychological Bulletin 114 (1993), pp. 413-434.

Bergman \& Magnusson, 1997 L. R. Bergman and D. Magnusson, A person-oriented approach in research on developmental psychopathology, Development and Psychopathology 9 (1997), pp. 291-319.

Boney-McCoy \& Finkelhor, $1995 \rightarrow$ S. Boney-McCoy and D. Finkelhor, Prior victimization: A risk factor for child sexual abuse and for PTSD-related symptomatology among sexually abused youth, Child Abuse and Neglect 19 (1995), pp. 1401-1421.

Bonner et al, 1999 B. L. Bonner, C. E. Walker and L. Berliner, Children with sexual behavior problems: Assessment and treatment (Final Report, Grant No. 90-CA1469, Washington, DC: Administration of Children, Youth, and Families, Department of Health and Human Services (1999); online http://www.calib.com/nccanch/pubs/ otherpubs/childassessment/index.cfm

Bronfenbrenner, $1979 \triangleright$ U. Bronfenbrenner, The ecology of human development, Harvard University Press, Cambridge, MA (1979).

Carpentier et al., 2006 M. Y. Carpentier, J. F. Silovsky and M. Chaffin, Randomized trial of treatment for children with sexual behavior problem: Ten-year follow-up, Journal of Consulting and Clinical Psychology 74 (2006), pp. 482-488.

Chaffin, 2008 M. Chaffin, Our minds are made up-Don't confuse us with the facts, Child Maltreatment 13 (2008), pp. 110-121.

Chaffin et al., 2008 M. Chaffin, L. Berliner, R. Block, T. Cavanagh-Johnson, W. N. Friedrich and D. G. Louis et al., Report of the ATSA Task Force on children with SBP, Child Maltreatment 13 (2008), pp. 199-218.

Chaffin et al., 2002 M. Chaffin, E. Letrourneau and J. F. Silvosky, Adults, adolescents, and children who sexually abuse children: A developmental perspective. In: J. E. B. Myers, L. Berliner, J. Briere, C. T. Hendrix, C. Jenny and T. A. Reid, Editors, The APSAC Handbook on Child Maltreatment (2nd Edition), Sage, Thousand Oaks, CA (2002), pp. 205-232.

Cicchetti, $1993 \longrightarrow$ D. Cicchetti, Developmental psychopathology: Reactions, reflections, projections, Developmental Review 13 (1993), pp. 471-502.

Cicchetti \& Lynch, 1993 D. Cicchetti and M. Lynch, Toward an ecological/transactional model of community violence and child maltreatment: Consequences for children's development, Psychiatry 53 (1993), pp. 96-118.

Cicchetti \& Rizley, $1981 \longrightarrow$ D. Cicchetti and R. Rizley, Developmental perspectives on the etiology, intergenerational transmission, and sequelae of child maltreatment, New Directions for Child Development 11 (1981), pp. 31-55.

Cicchetti \& Rogosch, 1996 D. Cicchetti and F. Rogosch, Equifinality and multifinality in developmental psychopathology, Development and Psychopathology 8 (1996), pp. 597-600.

Cicchetti \& Rogosch, 1997 D. Cicchetti and F. A. Rogosch, The role of self-organization in the promotion of resilience in maltreated children, Development and Psychopathology 9 (1997), pp. 797-815.

Cicchetti \& Sroufe, $2000 \rightarrow$ D. Cicchetti and L. A. Sroufe, Editorial: The past as a prologue to the future: The time, they've been achangin, Development and Psychopathology 12 (2000), pp. 255-264.

Cicchetti \& Toth, 1995 D. Cicchetti and S. L. Toth, A developmental psychopathology perspective on child abuse and neglect, Journal of the American Academy of Child and Adolescent Psychiatry 34 (1995), pp. 541-565.

Cohen \& Mannarino, $1996 \checkmark$ J. A. Cohen and A. P. Mannarino, Factors that mediate 
treatment outcome of sexually abused preschool children, Journal of the American Academy of Child and Adolescent Psychiatry 35 (1996), pp. 1402-1410.

Cohen \& Mannarino, 1998 J. A. Cohen and A. P. Mannarino, Factors that mediate treatment outcome of sexually abused preschool children: Six and 12-month follow-up, Journal of the American Academy of Child and Adolescent Psychiatry 37 (1998), pp. 44-51.

Cohen \& Mannarino, $2000 \triangleright$ J. A. Cohen and A. P. Mannarino, Predictors of treatment outcome in sexually abused children, Child Abuse and Neglect 24 (2000), pp. 983-994.

Collins et al., $2000>$ W. A. Collins, E. E. Maccoby, L. Steinberg, E. M. Hetherington and M. H. Bornstein, Contemporary research on parenting: The case for nature and nurture, American Psychologist 55 (2000), pp. 218-232.

Compas, 1987 B. E. Compas, Stress and life events during childhood and adolescence, Clinical Psychology Review 7 (1987), pp. 275-302

Cosentino et al., $1995 \rightarrow$ C. E. Cosentino, H. F. L. Meyer-Bahlburg, J. D. Alpert, S. L. Weinberg and R. Gaines, Sexual behavior problems and psychopathology symptoms in sexually abused girls, Journal of the American Academy of Child and Adolescent Psychiatry 34 (1995), pp. 1033-1042.

Crowe \& Bunclark, $2000 \longrightarrow$ M. Crowe and J. Bunclark, Repeated self-injury and its management, International Review of Psychiatry 12 (2000), pp. 48-53.

Cutler \& Nolen-Hoeksema, 1991 S. Cutler and S. Nolen-Hoeksema, Accounting for sex differences in depression through female victimization: Childhood sexual abuse, Sex Roles 24 (1991), pp. 425-438.

De Bellis et al., 1994 M. D. De Bellis, L. Lefter, P. K. Trickett and F. W. Putnam, Urinary catecholamine excretion in sexually abused girls, Journal of the American Academy of Child and Adolescent Psychiatry 33 (1994), pp. 320-327.

Drake, 1996 B. Drake, Unraveling “unsubstantiated. ", Child Maltreatment 1 (1996), pp. 261-271.

Eckenrode et al., 1993 J. Eckenrode, M. Laird and J. Doris, School performance and disciplinary problems among abused and neglected children, Developmental Psychology 29 (1993), pp. 53-62.

Elliot \& Briere, $1994 \longrightarrow$ D. M. Elliot and J. Briere, Forensic sexual abuse evaluations of older children disclosures and symptomatology, Behavioral Sciences \& the Law 12 (1994), pp. 261-277.

Everson et al., 1989 M. D. Everson, W. M. Hunter, D. K. Runyan, G. A. Edleson and M. L. Coulter, Maternal support following disclosure of incest, American Journal of Orthopsychiatry 59 (1989), pp. 197-207.

Feiring et al., $1998 \rightarrow$ C. Feiring, L. Taska and M. Lewis, The role of shame and attributional style in children's and adolescent's adaptation to sexual abuse, Child Maltreatment 3 (1998), pp. 129-142.

Frick \& Morris, $2004 \longrightarrow$ P. J. Frick and A. S. Morris, Temperament and developmental pathways to severe conduct problems, Journal of Clinical Child \& Adolescent Psychology 33 (2004), pp. 54-68.

Friedrich, $1993 \longrightarrow$ W. N. Friedrich, Sexual victimization and sexual behavior in children: A review of recent literature, Child Abuse \& Neglect 17 (1993), pp. 59-66.

Friedrich, 1997 W. N. Friedrich, Child sexual behavior inventory: Professional manual, PAR Psychological Assessment Resources, Inc (1997)

Friedrich, $1998-$ W. N. Friedrich, Behavioral manifestations of child sexual abuse, Child Abuse \& Neglect 22 (1998), pp. 523-531.

Friedrich, 2005 W. N. Friedrich, Correlates of sexual behavior in young children, Journal of Child Custody 2 (2005), pp. 41-55.

Friedrich, $2007-W$. N. Friedrich, Children with sexual behavior problems: Familybased, attachment-focused therapy, W. W. Norton, New York (2007)

Friedrich \& Trane, $2002 \square$ W. N. Friedrich and S. T. Trane, Sexual behavior in children across multiple settings, Child Abuse \& Neglect 26 (2002), pp. 243-245.

Friedrich et al., $1987 \rightarrow$ W. N. Friedrich, R. L. Beilke and A. Urquiza, Children from sexually abusive families: A behavioral comparison, Journal of Interpersonal Violence 2 (1987), pp. 391-402.

Friedrich et al., $1988>$ W. N. Friedrich, R. L. Beilke and A. J. Urquiza, Behavior problems in young sexually abused boys, Journal of Interpersonal Violence 3 (1988), pp. 21-28.

Friedrich et al., $2003 \gg$ W. N. Friedrich, W. H. Davies, E. Feher and J. Wright, Sexual behavior problems in preteen children: Developmental, ecological, and behavioral correlates, Annals of the N. Y. Academy of Sciences 989 (2003), pp. 95-104.

Friedrich et al., $1998-$ W. N. Friedrich, J. Fisher, D. Broughton, M. Houston and C. Shafran, Normative sexual behavior in children: A contemporary sample, Pediatrics 101 (1998), p. e9; online www.pediatrics.org/cgi/content/full/101/4/e9

Friedrich et al., 2001 W. N. Friedrich, J. Fisher, C. Dittner, R. Acton, L. Berliner and J. Butler et al., Child Sexual Behavior Inventory: Normative, psychiatric, and sexual abuse comparisons, Child Maltreatment 6 (2001), pp. 37-49.

Friedrich et al., $1991 \longrightarrow$ W. N. Friedrich, P. Grambsch, D. Broughton, J. Kuiper and R. L. Beile, Normative sexual behavior in children, Pediatrics 88 (1991), pp. 456-464.

Friedrich et al., $1992 \rightarrow$ W. N. Friedrich, P. Grambsch, L. Damon, S. K. Hewitt, C. Koverola and R. A. Lang et al., Child Sexual Behavior Inventory: Normative and clinical comparisons, Psychological Assessment 4 (1992), pp. 303-311.

Friedrich et al., $1997-$ W. N. Friedrich, T. M. Jaworski, J. E. Huxsahl and B. S. Bengtson, Dissociative and sexual behaviors in children and adolescents with sexual abuse and psychiatric histories, Journal of Interpersonal Violence 12 (1997), pp. 155-171.

Friedrich et al., $2000 \rightarrow$ W. N. Friedrich, T. G. M. Sandfort, J. Oostveen and P. T. CohenKettenis, Cultural differences in sexual behavior: 2-6 year old Dutch and American children, Journal of Psychology and Human Sexuality 12 (2000), pp. 117-129.

Friedrich et al., $1986 \checkmark$ W. N. Friedrich, A. J. Urquiza and R. L. Beilke, Behavior problems in sexually abused young children, Journal of Pediatric Psychology 11 (1986), pp. 47-57.

Garbarino \& Sherman, $1980>$ J. Garbarino and D. Sherman, High-risk neighborhoods and high-risk families: The human ecology of child maltreatment, Child Development 51 (1980), pp. 188-198.

Garcia Coll et al., $2000>$ C. G. Garcia Coll, A. Akerman and D. Cicchetti, Cultural influences on developmental processes and outcomes: Implications for the study of development and psychopathology, Development and Psychopathology 12 (2000), pp. 333-356.

Goldman \& Goldman, $1988 \longrightarrow$ R. J. Goldman and J. D. G. Goldman, The prevalence and nature of child sexual abuse in Australia, Australian Journal of Sex, Marriage and Family 8 (1988), pp. 94-106.
Gordon \& Schroeder, 1995 B. N. Gordon and C. S. Schroeder, Sexuality: A developmental approach to problems, Plenum Press, New York (1995).

Gray et al., 1997 A. Gray, A. Busconi, P. Houchens and W. D. Pithers, Children with sexual behavior problems and their caregivers: Demographics, functioning, and clinical patterns, Sexual Abuse: A Journal of Research and Treatment 9 (1997), pp. 267-290.

Gray et al., 1999 A. S. Gray, W. D. Pithers, A. Busconi and P. Houchens, Developmental and etiological characteristics of children with sexual behavior problems: Treatment implications, Child Abuse \& Neglect 23 (1999), pp. 601-621.

Hall et al., 1998 a D. K. Hall, A. Gray, A. Busconi, P. K. Houchens, F. Mathews and J. Pearce, Factors associated with sexual behavior problems: Identification of five distinct child types and related treatment considerations, Child Maltreatment 3 (1998), pp. 384-406.

Hall et al., 1998b D. K. Hall, F. Mathews and J. Pearce, Factors associated with sexual behavior problems in young sexually abused children, Child Abuse \& Neglect 22 (1998), pp. 1045-1063.

Hall et al., 2002 D. K. Hall, F. Mathews and J. Pearce, Sexual behavior problem in sexually abused children: A preliminary typology, Child Abuse $\mathcal{E}$ Neglect 26 (2002), pp. 289-312.

Haugaard, 1996 J. J. Haugaard, Sexual behaviors between children: Professionals opinions and undergraduates recollections, Families in Society: The Journal of Contemporary Human Services 77 (1996), pp. 81-89.

Haugaard \& Tilly, $1988-J$ J. J. Haugaard and C. Tilly, Characteristics predicting children's responses to sexual encounters with other children, Child Abuse \& Neglect 12 (1988), pp. 209-218.

Hibbard \& Hartman, 1992 - M. R. Hibbard and G. L. Hartman, Behavioral problems in alleged sexual abuse victims, Child Abuse and Neglect 16 (1992), pp. 755-762.

Hoyle, $2000 \triangleright$ S. Hoyle, The sexualized child in foster care, Child Welfare League of America Press, Washington, DC (2000).

Inderbitzen-Pisaruk et al., 1992 H. Inderbitzen-Pisaruk, C. R. Shawchuck and T. S. Hoier, Behavioral characteristics of child victims of sexual abuse: A comparison study, Journal of Clinical Child Psychology 21 (1992), pp. 14-19.

James et al., $2004 \rightarrow$ S. James, J. Landsverk, D. J. Slymen and L. K. Leslie, Predictors of outpatient mental health service use - the role of foster care placement change, Mental Health Services Research 6 (2004), pp. 127-141.

Jenkins \& Bell, 1997 E. J. Jenkins and C. C. Bell, Exposure and response to community violence among children and adolescents. In: J. D. Osofsky, Editor, Children in a violent society, Guilford Press, New York, NY (1997), pp. 9-31.

Kendall-Tackett et al., $1993 \rightarrow$ K. Kendall-Tackett, L. M. Williams and D. Finkelhor, Impact of sexual abuse on children: A review and synthesis of recent empirical studies, Psychological Bulletin 113 (1993), pp. 164-180.

Kilpatrick, 1986 A. C. Kilpatrick, Some correlates of women's childhood sexual experiences: A retrospective study, Journal of Sex Research 22 (1986), pp. 221-242.

Kolko et al., 1988 D. J. Kolko, J. T. Moser and S. R. Weldy, Behavioral/emotional indicators of child sexual abuse among child psychiatric inpatients: A comparison with physical abuse, Child Abuse \& Neglect 12 (1988), pp. 529-541.

Lamb \& Coakley, $1993 \rightarrow$ S. Lamb and M. Coakley, "Normal" childhood sexual play and games: Differentiating play from abuse, Child Abuse \& Neglect 17 (1993), pp. 515-526.

Långström et al., 2002 N. Långström, M. Grann and P. Lichtenstein, Genetic and environmental influences on problematic masturbatory behavior in children: A study of same-sex twins, Archives of Sexual Behavior 31 (2002), pp. 343-350.

Larsson \& Svedin, 2002a $\gg$ I. Larsson and C. G. Svedin, Teachers' and parents' reports on 3- to 6-year old childrens' sexual behavior-a comparison, Child Abuse E Neglect 26 (2002), pp. 247-266.

Larsson \& Svedin, 2002b $>$ I. Larsson and C. G. Svedin, Sexual experiences in childhood: Young adults' recollections, Archives of Sexual Behavior 31 (2002), pp. 263-273.

Larsson et al., 2000 I. Larsson, C. G. Svedin and W. N. Friedrich, Differences and similarities in sexual behavior among preschoolers in Sweden and USA, Nordic Journal of Psychology 54 (2000), pp. 251-257.

Laursen \& Hoff, 2006 B. Laursen and E. Hoff, Person-centered and variable-centered approaches to longitudinal data, Merrill-Palmer Quarterly 52 (2006), pp. 377-389.

Leifer et al., 1993 M. Leifer, J. P. Shapiro and L. Kassem, The impact of maternal history and behavior upon foster placement and adjustment in sexually abused girls, Child Abuse and Neglect 17 (1993), pp. 755-766.

Leiter \& Myers, $1994 \longrightarrow$ J. Leiter and K. A. Myers, Substantiated and unsubstantiated cases of child maltreatment: Do their consequences differ?, Social Work Research $\mathbf{1 8}$ (1994), pp. 67-82.

Letourneau et al., $2008 \rightarrow$ E. J. Letourneau, J. E. Chapman and S. K. Schoenwald, Treatment outcome and criminal offending by youth with sexual behavior problem, Child Maltreatment 13 (2008), pp. 133-144.

Letourneau et al., 2004 E. J. Letourneau, S. K. Schoenwald and A. J. Sheidow, Children and adolescents with sexual behavior problem, Child maltreatment $\mathbf{9}$ (2004), pp. 49-61.

Ligezinska et al., 1996 M. Ligezinska, P. Firestsone, I. G. Manion, J. McIntyre, R. Ensom and G. Wells, Children's emotional and behavioral reactions following the disclosure of extrafamilial sexual abuse: Initial effects, Child Abuse and Neglect 20 (1996), pp. 111-125.

Lindblad et al., 1995 F. Lindblad, P. A. Gustofsson, I. Larsson and B. Lundin, Preschoolers' sexual behavior at daycare centers: An epidemiological study, Child Abuse \& Neglect 19 (1995), pp. 569-577.

Livingston, 1987 R. Livingston, Sexually and physically abused children, Journal of the American Academy of Child and Adolescent Psychiatry 26 (1987), pp. 413-415.

Loeber \& Dishion, $1983 \rightarrow$ R. Loeber and T. Dishion, Early predictors of male delinquency: A review, Psychological Bulletin 94 (1983), pp. 68-99.

Loeber \& Stouthamer-Loeber, 1986 R. Loeber and M. Stouthamer-Loeber, Family factors as correlates and predictors of juvenile conduct problems and delinquency. In: M. Tonry, Editor, Crime and Justice vol. 7, University of Chicago Press, Chicago (1986), pp. 29-149.

Lopez Sanchez et al., $2002 \longrightarrow$ F. Lopez Sanchez, A. Del Campo and V. Guijo, Pre-pubertal sexuality, Sexologies 11 (2002), pp. 49-58.

Lynch \& Cicchetti, $1998 \longrightarrow$ M. Lynch and D. Cicchetti, An ecological-transactional analysis of children and contexts: The longitudinal interplay among child mal- 
treatment, community violence, and children's symptomatology, Development and Psychopathology 10 (1998), pp. 235-257.

Lynch et al., 1997 J. W. Lynch, G. A. Kaplan and S. J. Shema, Cumulative impact of sustained economic hardship on physical, cognitive, psychological, and social functioning, New England Journal of Medicine 337 (1997), pp. 1889-1895.

Manion et al., 1998 I. Manion, P. Firestone, P. Cloutier, M. Ligezinska, J. McIntyre and R. Ensom, Child extrafamilial sexual abuse: Predicting parent and child functioning, Child Abuse and Neglect 22 (1998), pp. 1285-1304.

Mannarino \& Cohen, $1990 \rightarrow$ A. P. Mannarino and J. A. Cohen, Treating the abused child. In: R. T. Ammerman and M. Hersen, Editors, Children at risk: An evaluation of factors contributing to child abuse and neglect, Springer, New York (1990), pp. 249-266.

Mannarino \& Cohen, 1996 A. P. Mannarino and J. A. Cohen, A follow up study of factors which mediate the development of psychological symptomatology in sexually abused girls, Child Maltreatment 1 (1996), pp. 246-260.

Mannarino et al., 1994 A. P. Mannarino, J. A. Cohen and S. Berman, The relationship between preabuse factors and psychological symptomatology in sexually abused girls, Child Abuse \& Neglect 18 (1994), pp. 63-71.

Mash \& Barkley, 1998 E. F. Mash and R. A. Barkley, Treatment of childhood disorders (2nd Ed. ), Guilford, New York (1998)

Mash \& Wolfe, 2005 E. J. Mash and D. A. Wolfe, Abnormal child psychology (3rd Ed), Thomson Wadsworth, Belmont, CA (2005).

McClellan et al., 1996 J. McClellan, C. McCurry, M. Ronnei, J. Adams, A. Eisner and M. Storck, Age of onset of sexual abuse: Relationship to sexually inappropriate behaviors, Journal of the American Academy of Child and Adolescent Psychiatry 35 (1996), pp. 1375-1383.

Melton, 1990 G. B. Melton, Child protection: Making a bad situation worse?, Contemporary Psychology 35 (1990), pp. 213-214.

Mennen and Meadow, $1995 \rightarrow$ F. E. Mennen and D. Meadow, The relationship of abuse characteristics to symptoms in sexually abused girls, Journal of Interpersonal Violence 10 (1995), pp. 259-274.

Merrick et al., 2008 M. T. Merrick, A. J. Litrownik, M. D. Everson and C. E. Cox, Beyond sexual abuse: The impact of other maltreatment experiences $\mathrm{n}$ sexualized behaviors, Child Maltreatment 13 (2008), pp. 122-132.

Meyer-Bahlburg et al., $2000 \triangleright$ H. F. L. Meyer-Bahlburg, C. Dolezal and D. E. Sandberg, The association of sexual behavior with externalizing behaviors in a community sample of prepubertal children, Journal of Psychology and Human Sexuality 12 (2000), pp. 61-79.

Mian et al., 1996 M. Mian, P. Marton and D. LeBaron, The effects of sexual abuse on 3- to 5-year-old girls, Child Abuse and Neglect 20 (1996), pp. 731-745.

Moffitt, 1993 - T. E. Moffitt, Adolescence-limited and life-course-persistent antisocial behavior: A developmental taxonomy, Psychological Review 100 (1993), pp. 674-701.

Newton et al., $2000 \gg$ R. R. Newton, A. J. Litrownik and J. A. Landsverk, Children and youth in foster care: Disentangling the relationship between problem behaviors and number of placements, Child Abuse and Neglect 24 (2000), pp. 1363-1374.

Noll et al., $2003-$ J. G. Noll, P. K. Trickett and F. W. Putnam, A prospective investigation of the impact of childhood sexual abuse on the development of sexuality, Journal of Consulting and Clinical Psychology 71 (2003), pp. 575-586.

O'Donnell et al., 1995 J. O'Donnell, J. D. Hawkins, R. F. Catalano, R. D. Abbott and L. E. Day, Preventing school failure, drug use, and delinquency among lowincome children: Long-term intervention in elementary schools, American Journal of Orthopsychiatry 65 (1995), pp. 87-100.

Paredes et al., $2001 \rightarrow$ M. Paredes, M. Leifer and T. Kilbane, Maternal variables related to sexually abused children's functioning, Child Abuse and Neglect 25 (2001), pp. 1159-1176.

Patterson, 1982 G. R. Patterson, Coercive family process: A social learning approach vol. 3, Castalia, Eugene, OR (1982).

Patterson, 2002 G. R. Patterson and M. Prior, The early development of coercive family processes. In: J. Reid, G. R. Patterson and J. Snyder, Editors, Antisocial behavior in children and adolescents: A developmental analysis and model for intervention, American Psychological Association, Washington, DC (2002), pp. 25-44.

Patterson et al., $2000 \triangleright$ G. R. Patterson, D. S. DeGarmo and N. Knutson, Hyperactive and antisocial behaviors: Comorbid or two points in the same process?, Development and Psychopathology 12 (2000), pp. 91-106.

Pelton, 1994 L. H. Pelton, The role of material factors in child abuse and neglect. In: G. B. Melton and F. D. Barry, Editors, Protecting children from abuse and neglect: Foundations for a new national strategy, Guilford Press, New York (1994), pp. 131-181.

Pithers et al., 1998 W. D. Pithers, A. Gray, A. Busconi and P. Houchens, Caregivers of children with sexual behavior problems: Psychological and familial functioning, Child Abuse \& Neglect 22 (1998), pp. 129-141.

Putnam, 2003 F. W. Putnam, Ten-year research update review: Child sexual abuse, Journal of the American Academy of Child and Adolescent Psychiatry 42 (2003), pp. 269-278.

Ray \& English, $1995-$ J. A. Ray and D. J. English, Comparison of female and male children with sexual behavior problems, Journal of Youth and Adolescents 24 (1995), pp. $439-451$

Reynolds et al., $2003 \rightarrow$ M. A. Reynolds, D. L. Herbenick and J. Bancroft, The nature of childhood sexual experiences: Two studies 50 years apart. In: J. Bancroft, Editor, Sexual development in childhood, Indiana University Press, Bloomington (2003).

Rieder \& Cicchetti, $1989 \triangleright$ C. Rieder and D. Cicchetti, Organizational perspective on cognitive control functioning and cognitive- affective balance in maltreated children, Developmental Psychology 25 (1989), pp. 382-393.

Rothbart and Bates, 2006 M. K. Rothbart and J. E. Bates, Temperament. In: W. Damon, R. Lerner and N. Eisenberg, Editors, Handbook of child psychology (6th ed), Social, emotional, and personality development, Vol. 3, Wiley, New York (2006), pp. 99-166.

Rothbaum \& Weisz, 1994 F. Rothbaum and J. R. Weisz, Parental caregiving and child externalizing behavior in nonclinical samples: A meta-analysis, Psychological Bulletin 116 (1994), pp. 55-74.
Rothbaum et al., $2000 \triangleright$ F. Rothbaum, J. Weisz, M. Pott, K. Miyake and G. Morelli, Attachment and culture: Security in the United States and Japan, American Psychologist 55 (2000), pp. 1093-1110.

Rutter, 1979 M. Rutter, Protective factors in children's response to stress and disadvantage. In: M. W. Kent and J. E. Rolf, Editors, Primary prevention of psychopathology, Vol. 3: Social competence in children, University Press of New England, Hanover, N. H. (1979), pp. 49-74.

Rutter, 1989 - M. Rutter, Pathways from childhood to adult life, Journal of Psychology and Psychiatry 30 (1989), pp. 23-51.

Rutter \& Sroufe, $2000 \rightarrow$ M. Rutter and L. Sroufe, Developmental psychopathology: Concepts and challenges, Development and Psychopathology 12 (2000), pp. 265-296.

Sameroff and Chandler, 1975 A. J. Sameroff and M. J. Chandler, Reproductive risk and the continuum of caretaker casualty. In: F. D. Horowitz, Editor, Review of child development research, Vol. 4, University of Chicago Press, Chicago (1975).

Sameroff et al., 1993 A. J. Sameroff, R. Seifer, A. Baldwin and C. Baldwin, Stability of intelligence from preschool to adolescence: The influence of social and family risk factors, Child Development 64 (1993), pp. 80-97.

Sandfort \& Cohen-Kettenis, $2000 \longrightarrow$ T. G. M. Sandfort and P. T. Cohen-Kettenis, Sexual behavior in Dutch and Belgian children as observed by their mothers, Journal of Psychology \& Human Sexuality 12 (2000), pp. 105-115.

Sanson \& Prior, 1999 A. Sanson and M. Prior, Temperament and behavioral precursors to oppositional defiant disorder and conduct disorder. In: H. C. Quay and A. E. Hogan, Editors, Handbook of disruptive behavior disorders, Kluwer, New York (1999), pp. 397-418

Santtila et al., 2005 P. Santtila, N. K. Sandnabba, M. Wannäs and J. Krook, Multivariate structure of sexual behaviors in children: Associations with age, social competence, life stressors, and behavioral disorders, Early Child Development and Care $\mathbf{1 7 5}$ (2005), pp. 3-21.

Schoentjes et al., 1999 E. Schoentjes, D. Deboutte and W. Friedrich, Child sexual behavior inventory: A Dutch-speaking normative sample, Pediatrics 104 (1999), pp 885-893.

Schwab-Stone et al., 1995 M. E. Schwab-Stone, T. S. Ayers, W. Kasprow, C. Voyce, C. Barone, T. Shriver and R. P. Weissberg, No safe haven: A study of violence exposure in an urban community, Journal of the American Academy of Child and Adolescent Psychiatry 34 (1995), pp. 1343-1352.

Silovsky \& Bonner, 2003 J. Silovsky and B. L. Bonner, Sexual behavior problems In: T. H. Ollendick and C. S. Schroeder, Editors, Encyclopedia of Clinical Child and Pediatric Psychology, Kluwer Press, New York (2003), pp. 589-591.

Spaccarelli, 1994 S. Spaccarelli, Stress, appraisal, and coping in child sexual abuse A theoretical and empirical review, Psychological Bulletin 116 (1994), pp. 340-362.

Stern et al., 1995 A. E. Stern, D. L. Lynch, K. R. Oates, B. I. O'Toole and G. Cooney, Self-esteem, depression, behaviour, and family functioning in sexually abused children, Journal of Child Psychology and Psychiatry 36 (1995), pp. 1077-1089.

Strassberg et al., $1994>$ Z. Strassberg, K. A. Dodge, G. S. Pettit and J. E. Bates, Spanking in the home and children's subsequent aggression toward kindergarten peers, Development and Psychopathology 6 (1994), pp. 445-461.

Seto \& Barbaree, $1999 \checkmark$ M. C. Seto and H. E. Barbaree, Psychopathy, treatment behavior, and sex offenders recidivism, Journal of Interpersonal Violence 14 (1999), pp. $1235-1248$.

Silovsky \& Niec, 2002 J. F. Silovsky and L. Niec, Characteristics of young children with sexual behavior problems: A pilot study, Child Maltreatment 7 (2002), pp. 187-197.

Smith \& Howard, 1994 S. L. Smith and J. A. Howard, The impact of previous sexual abuse on children's adjustment in adoptive placement, Social Work 39 (1994), pp. 491-501.

Tarren-Sweeney, 2008 M. Tarren-Sweeney, Predictors of problematic sexual behavior among children with complex maltreatment histories, Child Maltreatment 13 (2008), pp. 182-198.

Thigpen et al., 2003 J. W. Thigpen, E. M. Pinkston and J. H. Mayefsky, Cross-cultural aspects - the African American perspective. In: J. Bancroft, Editor, Sexual development in childhood, Indiana University Press, Bloomington (2003), pp. 241-254.

Thomas and Chess, 1977 A. Thomas and S. Chess, Temperament and development, Brunner-Mazel, New York (1977)

Tong et al., $1987 \longrightarrow$ L. Tong, K. Oates and M. McDowell, Personality development following sexual abuse, Child Abuse \& Neglect 11 (1987), pp. 371-383.

Trickett et al., $2001>$ P. K. Trickett, J. G. Noll, A. Reiffman and F. W. Putnam, Variants of intrafamilial sexual abuse experience: Implications for short- and long-term development, Development and Psychopathology 13 (2001), pp. 1001-1019.

Trickett et al., $1997 \longrightarrow$ P. K. Trickett, A. Reiffman, L. A. Horowitz and F. W. Putnam Characteristics of sexual abuse trauma and the prediction of developmental outcomes. In: D. Cicchetti and S. L. Toth, Editors, Developmental perspectives on trauma: Theory, research, and intervention, University of Rochester Press, Rochester, NY (1997), pp. 289-314

U. S. Department of Health and Human Services, 1993 U. S. Department of Health and Human Services (DHHS). (1993). The National Survey of Current \& Former Foster Parents. Washington, DC: National Clearinghouse on Child Abuse and Neglect Information.

Wells et al., 1997 R. D. Wells, J. McCann, J. Adams, J. Voris and B. Dahl, A validation study of the Structured Interview of Symptoms Associated with Sexual Abuse (SASA) using three samples of sexually abused, allegedly abused, and nonabused boys, Child Abuse and Neglect 2 (1997), pp. 1159-1168.

Wells et al., $1995 \rightarrow$ R. D. Wells, J. McCann, J. Adams, J. Voris and J. Ensign, Emotional, behavioral, and physical symptoms reported by parents of sexually abused, nonabused, and allegedly abused prepubescent females, Child Abuse and Neglect 19 (1995), pp. 155-163

Wolfe et al., 1991 V. V. Wolfe, C. Gentile, T. Michienzi, L. Sas and D. A. Wolfe, The children's impact of traumatic events scale: A measure of post-sexual abuse PTSD symptoms, Behavioral Assessment 13 (1991), pp. 359-383.

Young et al., $1994 \rightarrow$ R. E. Young, T. A. Bergandi and T. G. Titus, Comparison of the effects of sexual abuse on male and female latency-aged children, Journal of Interpersonal Violence 9 (1994), pp. 291-306. 